Structures, 31 (2021), 940-960.

https://doi.org/10.1016/j.istruc.2021.02.023

\title{
Assessment and Design Considerations for Single Layer Cylindrical Lattice Shells Subjected to Seismic Loading
}

\author{
F. Cedrón and A. Y. Elghazouli* \\ Department of Civil and Environmental Engineering, Imperial College London, UK
}

\begin{abstract}
This paper examines the main considerations related to the seismic design and assessment of single layer steel cylindrical lattice shells, and offers recommendations for their practical application. Geometric configurations covering a wide range of rise to span ratios are considered within the investigation. An insight into the relative influence of seismic loading on shell design, in comparison to gravity conditions, is firstly provided through the use of digital parametric engineering procedures. This is followed by linear elastic response assessments which are used to propose a simplified procedure for estimating the internal seismic forces for the purpose of member sizing in early design stages. Suitable approaches for pushover analysis are then discussed and used to identify inherent plastic mechanisms. The results of incremental nonlinear dynamic analysis, using a suite of fourteen records, are also employed in order to validate the findings and to further assess the ultimate response under realistic seismic loading conditions. Based on the findings, representative ranges for behaviour factors and displacement modification coefficients are derived alongside discussions on their implementation within codified seismic design procedures. Apart from providing recommendations for simplified design approaches, the assessments presented in this paper can also be used to support detailed performance based guidelines as well as for informing geometry and size optimisation strategies.
\end{abstract}

Keywords: Seismic design; cylindrical lattice shells; pushover response; incremental dynamic analysis; behaviour factors; displacement modification coefficients.

\section{Corresponding Author:}

Prof. A. Y. Elghazouli, Department of Civil \& Environmental Engineering, Imperial College London, UK. Email: a.elghazouli@ic.ac.uk 


\section{Introduction}

Single layer cylindrical lattice shells represent a structural form that is well suited for spanning over large rectangular open spaces, such as train stations, exhibition halls, sports arenas, or airplane hangars. They usually consist of a single layer of members, typically of steel hollow cross-sections, arranged in a triangulated grid following the geometry of a cylindrical surface, and are ideal for a roof over a column-free area. The connections between the lattice elements may vary, but are often selected to be continuous so as to enhance local and global stability.

Lattice shell structures are normally designed primarily for gravity loads, as their lightweight nature is ideal for large spans. Accordingly, their design for global stability under gravity loads has been studied extensively [1-9], for a wide array of configurations such as elliptic paraboloids [10, 11], spherical domes [12, 13], and cylindrical vaults [14-19]. In contrast, their design for seismic actions has received relatively less attention, particularly in terms of practical design considerations that can be used in codified guidance. This was pointed out in several previous studies such as that by Saka and Taniguchi [20] which reported the damage caused by the 1995 Hyogoken-Nanbu earthquake in Japan to spatial structures, including several single layer cylindrical lattice shell roofs in gymnasia. Their observations highlighted the significant stresses experienced by the edge arches of the shells. The need for more research on the seismic behaviour of these shells was identified, including more detailed assessment and understanding of their collapse mechanisms.

Several recent studies have hence focused on assessing the failure mechanisms and key damage areas in shells subjected to seismic loading. For example, Qi et al [21] examined the different damage modes of spherical lattice domes and cylindrical lattice vaults. It was suggested that the combination of member buckling and joint fractures was the driving cause of instability and failure in the shells. Also, Shen et al. [22] used a single specific intensity from the Chinese code for both spectral and time history analyses on a cylindrical lattice structure, and the diagonal members were identified as the main resisting elements. The structure was shown to exhibit significant reserve capacity, remaining largely in the elastic range. Another study by Zhi et al. [23] offered some insight into the failure mechanisms, and classified these as either strength dominated, typical for higher length to span ratios, or dynamic instability, often observed in shells with lower aspect ratios. Other experimental and numerical studies by Ma et al. [24, 25] included shells and spherical domes with semi-rigid joints, and showed that the bending stiffness of the joints plays an important role in the dynamic response of such lattice shells.

Aside from examining the modes of failure, several studies have considered the detailed seismic response of lattice shells, although mostly covering the linear elastic range only. Such is the case in the numerical and experimental study by Shin et al. [26] on double layer barrel 
vaults. Particular focus was given to the effect of different subtended angles, essentially producing different rise to span ratios. The behaviour was found to be governed by the open angle, with an increase in the influence of the horizontal component of seismic loading as the angle increased in shells of larger rise. The vertical component was shown to affect more the shells with a smaller open angle, although it had less of an impact altogether. In another study, Takeuchi et al. [27] investigated the linear elastic seismic response of shells supported by a conventional substructure of columns where most of the demand was concentrated, and proposed a series of acceleration amplification factors. Also, Shen et al. [28] examined the maximum stresses produced by horizontal and vertical excitations through three linear elastic time history analyses. Force coefficients were proposed as the ratio of bending moment or axial actions from seismic loads to those produced by gravity loads. The study was limited to one specific intensity scale from the Chinese code. Similarly, Chen et al. [29] assessed the seismic response of single layer cylindrical lattice shells using time history analysis, and suggested similar force coefficients. Again, only linear elastic response was considered in the study. Moreover, only axial forces were considered for identifying the main trends, while bending moments and forces in the edge arches were not taken into account.

In comparison with the various studies that have considered the seismic response of single layer lattice structures, primarily in the linear elastic range and for pre-defined intensity levels, design-oriented assessments have been limited. A recent study by Khalili et al. [30] considered possible force modification and displacement amplification factors for single layer barrel vaults using time history analysis, and the equal displacement rule was shown to be generally applicable for these structures. The dearth of focused design assessments was highlighted in a detailed state of the art review by Nazakawa et al. [31] on the seismic design and analysis of steel spatial structures. It is noted that, despite the significant interest in lattice shell structures, and the availability of various recommendations based on collated background studies [32], there is still no universally accepted procedure for their seismic design, particularly in terms for the inelastic range. To this end, current European seismic codes do not include specific guidance for lattice shell structures [33].

This paper examines the main considerations related to the seismic design and assessment of single layer steel cylindrical lattice shells. It builds on previous detailed assessments by the authors [34] into the nonlinear inelastic seismic performance of cylindrical lattice shells. The relative influence of seismic loading compared to gravity conditions is firstly examined using digital parametric engineering procedures. A simplified procedure for estimating the internal seismic forces for the purpose of member sizing in early design stages is then proposed based on the results of linear elastic analysis. Nonlinear inelastic pushover and incremental dynamic assessments are also used to assess internal force distributions and ultimate failure modes. From the findings, recommendations for practical application in performance based seismic 
design are outlined, and behaviour factors and force modifications coefficients for use in simplified code design procedures are proposed and discussed.

\section{Structural Form}

\subsection{Geometric Configuration}

The single layer cylindrical lattice shell configuration considered in this paper is depicted in Figure 1. This structural topology, involving a three-way lattice arrangement with longitudinal members parallel to the axis of the cylinder, is extensively used in practice and shown to be very efficient in resisting both symmetrical and asymmetrical loads [3, 5, 7, 35]. The shells are defined by their span, rise, and length, denoted B, H, and L, respectively. The nodes of the edge arches follow circular arcs. The X-direction is parallel to these edge arches, the Y-direction is along the longitudinal axis of the cylindrical shell, and the Z-direction is vertical. The shells considered in this study are pinned at the supports of the two longitudinal edges, with the edge arches unrestrained. These boundary conditions are considered to be most commonly found in design practice, where openings or non-structural glass façades are located at the ends of the shells. The shells in this study are assumed to have a direct connection to a firm foundation at ground level, and hence no substructure is considered, which would otherwise have a notable influence on the response [32]. The gravity loading is defined as a surface load, $\mathrm{q}$, in $\mathrm{kN} / \mathrm{m}^{2}$, and is applied vertically on the nodes based on each of their tributary areas, as well as contributing to the mass in dynamic analysis.

\subsection{Parametric Assessment}

The parametric structural engineering tool Karamba3D [36] was firstly used to perform an initial comparison into the forces induced in the members from gravity loads to those generated from lateral actions. It is worth noting that Karamba3D is a structural analysis plug-in for Grasshopper [37], the digital parametric modelling tool used with the CAD modelling software Rhinoceros [38]. Grasshopper offers the possibility of building a model parametrically, readily enabling a change of geometry for multiple analyses through Karamba3D. This offers a useful and computationally efficient exploratory tool for early design stages, by running simple linear elastic analyses on multiple models.

To provide an initial insight into the influence of seismic loads, two load cases were considered, namely a gravity case and a lateral earthquake case. Although the vertical component of seismic loading can have an influence on the response, especially for shells of low $\mathrm{H} / \mathrm{B}$, as shown in a previous study by the authors [34], this preliminary assessment was carried out in order to compare the influence of lateral seismic loading to vertical gravity loads, and hence focuses on only the horizontal component. For the purpose of this simplified exploratory assessment, the seismic loading was represented by statically applying, in the 
horizontal X direction, a percentage of the gravity loads. Even though gravity loads and lateral earthquake loads would act simultaneously in practice, they have been separated in this schematic study. This was considered so as to better analyse their influence on the shell design independently, and to capture the general trends due to shell geometry and loading. The length and span were fixed at $27 \mathrm{~m}$ and $15 \mathrm{~m}$, respectively. To determine the influence of key parameters, the rise to span ratio covered a practical range of $\mathrm{H} / \mathrm{B}$ from 0.1 to 0.5 , the applied gravity load was varied between $0.5 \mathrm{kN} / \mathrm{m}^{2}$ and $4.0 \mathrm{kN} / \mathrm{m}^{2}$, and the fraction of gravity load applied horizontally varied from $0.05 \mathrm{~g}$ to $0.50 \mathrm{~g}$.

The study made use of the cross-section optimization algorithm in Karamba3D. A list of available cross-sections is defined in the model in ascending order of cross-sectional area. The program then runs the model with the lowest member size, and performs all relevant Eurocode 3 checks [39]. If the sections are deemed satisfactory, they are maintained, otherwise they are increased in size to the next available section. The analysis is then rerun, and the new members are checked against the new forces. This process is iteratively repeated until the program converges to a valid solution. To avoid an unrealistic and impractical model with numerous section sizes, all longitudinal members and all diagonal members were independently grouped using the same circular hollow section sizes for each group respectively.

\subsection{Comparative Characteristics}

The parametric assessment offers an initial insight into the comparative influence of seismic versus gravity loads for this structural configuration. As depicted in Figure 2, the highest demand under lateral loading is at the quarter points of the shell. This was the case across all values of $\mathrm{H} / \mathrm{B}$. Using the cross-section optimization algorithm, the cross sectional areas of the circular hollow sections used for the diagonal members, as obtained from gravity-only or lateral loads, are compared in Figure 3. It should be noted that diagonal members represent the main load carrying elements in these shells, as shown in an earlier study by the authors [34]. As H/B increases, larger sizes of members are needed, as depicted in Figure 3a. For values of $\mathrm{H} / \mathrm{B}$ greater than 0.20 , the cross-sectional area required to resist horizontal loads starts from $0.20 \mathrm{~g}$ to become greater than that required for gravity loads. Considering the effect of the mass of the structure, as shown in Figure 3b, a similar pattern is observed. Larger sizes are needed as the applied load increases for both load cases, as the horizontal seismic loads also increase with the mass of the structure. Again, the horizontal load case starts to govern from levels of $0.20 \mathrm{~g}$.

The same trends as those discussed above can be observed by comparing the total self-weight of the structure, as shown in Figure 4. The ratio of the self-weight of the structure designed solely for gravity loads to that designed for horizontal loads is depicted. When this ratio is greater than 1.0, it indicates that larger members are needed to resist the horizontal 
loads case than the vertical one and, hence, the earthquake load case would govern in sizing the elements. The self-weight ratio starts to exceed unity when the fraction of gravity load applied horizontally reaches $0.20 \mathrm{~g}$. This is the case for all levels of applied load on the structure. The same trend is observed in shells of $\mathrm{H} / \mathrm{B}$ ratios above 0.20 yet, for shallower shells of lower H/B ratios, a higher percentage of gravity load applied horizontally needs to be reached for it to govern. Shells with relatively low rise have more inclined members and are thus more suited for resisting horizontal loads. Their design would likely be governed more by resistance to gravity loads rather than to seismic loads.

\section{Estimation of Seismic Forces}

\subsection{Preliminary Design}

For the studies considered subsequently in this paper, shells with a wide range of $\mathrm{H} / \mathrm{B}$, between 0.1 and 0.5 , with an increment of 0.05 , were designed following standard procedures in Eurocode 3 [33] and Eurocode 8 [39], as well as existing shell buckling design recommendations $[4,5,9,14]$. The span and length were again maintained at $15 \mathrm{~m}$ and $27 \mathrm{~m}$, respectively. The shells were designed using the program SAP2000 [40], considering the selfweight, a superimposed dead load (DL) of $1.0 \mathrm{kN} / \mathrm{m}^{2}$, and a live load (LL) of $1.0 \mathrm{kN} / \mathrm{m}$, following the gravity load combination of 1.35 DL + 1.50 LL. The design used S275 steel, with a yield strength of $\mathrm{f}_{\mathrm{y}}=275 \mathrm{~N} / \mathrm{mm}^{2}$ and a modulus of elasticity $\mathrm{E}=210,000 \mathrm{~N} / \mathrm{mm}^{2}$.

The default lateral load case (EQ) in SAP2000 was used as an initial approximation to seismic loading, in which loads are applied proportional to the height of the nodal masses, using a Spectrum Type 1, Ground Type C, and $\mathrm{ag}=0.25 \mathrm{~g}$, based on Eurocode 8 and a load combination of 1.0 DL + 0.3 LL + 1.0 EQ. Although this is intended for regular building structures, this default load pattern offers a useful preliminary estimate. Wind loading was not considered in this case, and was assumed not to have a governing influence on the design. A buckling analysis, including P-Delta effects and large displacements, was also carried out to design the shells for stability. The gravity load was increased as follows: $1.35 \mathrm{DL}+1.50$ $\mathrm{LL}+\lambda \cdot(1.35 \mathrm{DL}+1.50 \mathrm{LL})$. The sizes of members, all circular hollow sections, were increased until a buckling load factor of $\lambda=1.0$ was achieved [14], in cases that were driven by buckling, or until Eurocode 3 resistance limits were reached, in cases driven by strength. The characteristics of the shells resulting from this preliminary design are shown in Table 1.

\subsection{Prediction of Dynamic Characteristics}

For estimating the seismic forces for preliminary design purposes, the dynamic characteristics are required. To this end, the fundamental period as well as the corresponding mode shape and mass participation factor can be estimated from simplified relationships, in the absence of 
a detailed eigenvalue analysis. The fundamental period can be determined using Equation (1), based on a recent study by the authors [34], as follows:

$$
\begin{gathered}
T_{1}=C_{\kappa} \cdot 2 \pi(\theta R)^{2} \cdot\left[\frac{1+\frac{3}{4}\left(\frac{\theta}{\pi}\right)^{2}}{\theta^{4}-8 \pi^{2} \theta^{2}+16 \pi^{4}}\right]^{1 / 2} \cdot \sqrt{\frac{3 A\left(1-v^{2}\right) \rho}{E I}} \\
C_{\kappa}=0.9-0.1 \cdot\left(\frac{H}{B}\right)
\end{gathered}
$$

where $T_{1}$ is the fundamental period, $\mathrm{C}_{\mathrm{K}}$ is a correction factor to account for shell curvature, $\theta$ is the half subtended angle of the shell, $\mathrm{R}$ is the radius, $\mathrm{A}$ is the area of members, $v$ is Poisson's ratio, $\rho$ is density, $\mathrm{E}$ is Young's modulus, and I is moment of inertia of the section. This theoretical prediction equation was derived for shells with the topology depicted in Figure 1, for any length, span, and rise, and assuming all the members have the same section, and an angle of $60^{\circ}$ between longitudinal and diagonal members, which is often the case. Deviations from these conditions will still produce reasonable estimates for preliminary design, as shown in a previous study by the authors [34].

The first mode shape and its associated geometric parameters are as depicted in Figure 5, and following the equations given below [34]:

$$
\begin{gathered}
x=\sin \frac{2 \pi \alpha}{\theta} \\
z=\frac{\theta}{2 \pi}\left(1-\cos \frac{2 \pi \alpha}{\theta}\right)
\end{gathered}
$$

The first mode mass participation factor, $\gamma_{1}$, can be approximated by a simple sinusoidal relationship with the rise to span ratio. The mass, length to span ratio, and member sizes, do not significantly alter this relationship, which is dependant only on $\mathrm{H} / \mathrm{B}$ as follows:

$$
\gamma_{1}=0.54 \sin \left[4.89\left(\frac{H}{B}-0.19\right)\right]+0.35
$$

The above relationship holds true for $\mathrm{H} / \mathrm{B}$ between 0.05 and 0.50 , which cover realistic practical ranges. Values of the first mode mass participation factor of typical shells are depicted in Figure 6 [34], along with the prediction relationship from Equation (5).

\subsection{Prediction of Internal Seismic Forces}

Although the vertical seismic component can have a notable effect on the response [34], the horizontal component is predominantly the most critical in terms of the magnitude of internal forces induced in the shells [26, 34, 41]. Furthermore, the bending moments are typically more critical in governing the member sizes, as shown in previous studies [28, 34]. It follows that an accurate prediction of the bending moments produced by the horizontal seismic component would be the most critical in the preliminary design stage. In order to address this, 
the shape of the first mode is used to create an idealised load pattern. The first mode shape includes both horizontal and vertical displacements of the nodes, with the proportion of these varying depending on $\mathrm{H} / \mathrm{B}$. Hence, apart from its suitability for predicting the bending moments in the shells, it can also capture the vertical effects produced by horizontal accelerations in shells of lower $\mathrm{H} / \mathrm{B}$, as well as serving as a proxy for the effects produced by vertical accelerations. Even though shells of low $\mathrm{H} / \mathrm{B}$ are not typically dominated by their first mode in terms of mass participation, the specific procedure proposed herein is still shown to offer an adequate initial approximation to capture the cumulative effects of higher modes, and provides an estimate of the forces for preliminary sizing of members, as assessed below.

The suggested procedure considers the combination of two linear elastic load cases. The first load case corresponds to the gravity loads employed in a seismic analysis, that is, the dead load plus $30 \%$ of the live load. As described above, the second load case corresponds to the loads proportional to the first mode shape, as depicted in Figure 7 for three representative $\mathrm{H} / \mathrm{B}$ values. However, as the modal shapes are unitless, appropriate scaling is required to capture the level of loading experienced in a particular seismic scenario.

The approach proposed herein is to scale the loads in proportion to the first mode shape such that the horizontal base shear produced, $\mathrm{V}$, is equal to the product of the first mode mass participation factor, $\gamma_{1}$, the mass of the structure, $\mathrm{m}$, and the first mode spectral acceleration, $\mathrm{S}_{\mathrm{a}}\left(\mathrm{T}_{1}\right)$, obtained from the relevant response spectrum (as described in Section 3.1), as follows:

$$
V=\gamma_{1} \cdot m \cdot S_{a}\left(T_{1}\right)
$$

As shown in Figure 7, the loads corresponding to the first mode in shells of low H/B have a large vertical component. As such, the scaling factor needed to produce a significant horizontal base shear would be relatively large, as their horizontal components are insignificant. This is however mitigated by the proportional relationship between the first mode mass participation factor and $\mathrm{H} / \mathrm{B}$. The first mode mass participation factor serves as a shape factor that reduces the large loads that would otherwise be applied for shells of low $\mathrm{H} / \mathrm{B}$, hence overestimating the forces.

\subsection{Comparison with Time History Results}

In order to assess the accuracy of the internal forces produced by seismic actions as predicted by the above proposed estimation procedure, they are compared herein with the internal forces obtained under realistic seismic loading conditions. For this purpose, time history analysis was carried out on the same shells. Seven strong motion records matching Eurocode 8 Type 1 Spectrum, with Soil Type $\mathrm{C}$, and $\mathrm{a}_{\mathrm{g}}=0.25 \mathrm{~g}$ were chosen by scaling the records to minimise the root mean square spectral difference in the period range of $0.2 \mathrm{~s}$ to $2.0 \mathrm{~s}$. A summary of these records and their characteristics is given in Table 2. The analysis was 
carried out by applying these records in the X-direction using the open source nonlinear analysis program OpenSees [42], with force-based beam-column elements used to model the members. The longitudinal component, i.e. horizontal in the $\mathrm{Y}$ direction, has not been included, as the shells are very stiff in this direction compared to other directions. The member response in this direction is principally axial, with very minor bending moments. Since the axial forces produced are well within the capacity of the members, this component does not have a significant influence on the behaviour and design.

The bending moments and axial forces resulting from the application of the sum of gravity loads and those proportional to the first mode shape were measured in the edge and diagonal members with the highest magnitude (shown in red and green, respectively, in Figure 1). Figure 8 and Figure 9 compare the axial forces and bending moments, respectively, obtained by this proposed prediction method and the mean of the peak forces obtained from linear time history, for five representative values of H/B. The horizontal axis represents the eight members studied for each case, with the tick marks indicating the different members. The maximum and minimum peak forces from the seven records are also shown in the plots to illustrate the full response ranges, although the average of the response quantities is what will be relevant for design, as seven records were used to obtain these internal forces, as stipulated in the provisions of Eurocode 8 [33].

The axial forces shown in Figure 8 indicate that the overall distribution is generally well replicated by the prediction method using the first mode shape as a force profile. There is only a slightly larger discrepancy in the two central members, where the lateral force case shows reduced axial forces. The first mode shape does not have a vertical component at the central node, and hence the axial forces on these members are slightly lower, as they would be produced by the influence of higher modes. This is especially prominent in shells of higher $\mathrm{H} / \mathrm{B}$, as the central members would have a more vertical inclination than in shallower shells. Nonetheless, this is the point at which the forces are lowest, and hence has no influence on the design. Similarly, the bending moments shown in absolute values in Figure 9 also indicate close correlations. The prediction method captures faithfully the average bending moment distribution of the time history results in the edge arch, producing similar shapes with accurate positions of maxima and minima as well as comparable values.

Overall, the prediction method slightly underestimates the mean axial forces of the seven time history analyses. The bending moments, on the other hand, are generally very close, and only slightly overestimated in some cases. The average differences between the estimated internal forces and those obtained from time history are summarised in Table 3. It is shown that the proposed approach predicts the bending moments in the members, with an average difference of $9 \%$, but is slightly less accurate for axial forces with an average difference of $12 \%$ lower than the time history results. It is also worth noting that although the average 
values and general shapes of the internal forces are well represented, prediction of the maximum values in the shell would be more important for design as these would govern the member sizes. To this end, Table 4 shows the differences in the prediction of these maximum axial forces and bending moments, indicating better accuracy compared to the averages.

As noted previously, the bending moments have the most significant influence on the member sizes when considering seismic actions. The close predictions of bending moments obtained using the proposed prediction method, with the first mode shape as a force profile, offers a useful tool for preliminary design. Even though the first mode has a lower mass participation ratio than in conventional structures, especially for shells of lower $\mathrm{H} / \mathrm{B}$ ratio, the forces obtained are adequate for preliminary stages of design, without the need for investigating higher modes. The remaining modes that contribute to the lateral response of the shell are dispersed, often with no modes mobilising more than $5 \%$ of the mass $[28,34]$. The higher modes that have greater contributions all have very low periods and are relatively stiff, and are hence less affected by the range of frequencies within seismic excitations.

\subsection{Proposed Design Procedure}

The proposed steps to estimate the internal elastic seismic forces for member sizing in a single layer cylindrical lattice shell are summarised below. The scope of this estimation procedure is for the preliminary design of the shells, to obtain an initial reliable estimate of the seismic forces that are induced in the members for their design. It would be recommended to use the forces obtained in this manner to size the members, as more representative designs would be achieved than using the default loads proportional to height, which current design software and structural codes typically assume as default.

1. Determine the first mode period from Equations (1) and (2), first mode shape from Equations (3) and (4), and first mode mass participation ratio from Equation (5).

2. Carry out static linear analysis using the gravity load case and a load case with loads proportional to the first mode nodal displacements.

3. Scale the load case corresponding to the first mode such that the base shear is equal to the product of the first mode mass participation ratio, the mass of the structure, and the first mode spectral acceleration, according to Equation (6).

4. Add the scaled first mode load case to the gravity load case and use the resulting internal actions for the sizing of members.

\section{Pushover Response}

\subsection{Analysis Procedures}

In order to examine the nonlinear inelastic static behaviour of structures, pushover analysis is often used in assessment and design. This section outlines the main considerations related specifically to the pushover analysis of shell structures. For this purpose, pushover analysis 
was carried out using OpenSees [42] on the shells described in Section 3.1. Gravity loads were applied in an initial step, again for a dead load and a live load of $1.0 \mathrm{kN} / \mathrm{m}^{2}$ each, using the combination of 1.0 DL $+0.3 \mathrm{LL}$. Loads proportional to the displacements of the first mode of vibration were then applied incrementally, displacement controlled using the top node of one of the edge arches. Two sets of analyses were performed, with and without geometric nonlinearities, for comparison. The results are summarised in Table 5.

In order to capture the deformations that shell structures undergo, a damage measure proposed recently by the authors [34] and referred to as the peak angle change, $\Delta_{\theta, \max }$, is best used. This parameter represents the largest change in each of the individual angles of the edge arch, with respect to the undeformed geometry, as depicted in Figure 10 [34]. The peak angle change depicts deformation in the shells more faithfully than drift, as the latter can obscure deformations in shells of low H/B, as depicted in Figure 11, which shows the pushover curves generated by the shells studied in terms of the two damage measures.

\subsection{Main Response Parameters}

Pushover analysis can be used to select a reference yield point which can be used in various assessment procedures. From an earlier study by the authors [34], it was shown that the most appropriate point for first yield for such shell structures corresponds to any of the members of the edge arch exceeding the plastic interaction condition given in Equation (7) below, where $\mathrm{M}_{\mathrm{y}}$ and $\mathrm{M}_{\mathrm{z}}$ are the major and minor axis bending moments, $\mathrm{M}_{\mathrm{pl}}$ is the plastic moment capacity of the section, $\mathrm{N}$ is the axial force, and $\mathrm{N}_{\mathrm{pl}}$ is the axial capacity of the member.

$$
\frac{M_{y}}{M_{p l}}+\frac{M_{z}}{M_{p l}}+\left(\frac{N}{N_{p l}}\right)^{2} \leq 1
$$

This yield point is marked on the pushover plots in Figure 11, once again showing that the peak angle change is better suited to describe the nonlinear response as there is less dispersion compared to drift, and can thus serve as an appropriate measure to compare shells of different H/B. Once this point has been established, the overstrength due to redistribution can be obtained, referred to as $\alpha_{\mathrm{u}} / \alpha_{1}$ in Eurocode 8 [33] or as $\mathrm{q}_{\mathrm{R}}$ in its draft revision [43], reflecting the ratio of the maximum base shear to the base shear at first yield. The values for this factor range between 1.20 and 1.33, as shown in Table 5.

In addition to the yield point and overstrength due to redistribution, pushover analysis can also serve to characterise the plastic mechanisms of the shells. To this end, Figure 12 depicts the spread of plasticity in the edge arches of shells of varying $\mathrm{H} / \mathrm{B}$ by numbering the plastic hinges in the order in which they develop [34]. The first hinge forms in the same place for all the shells, but then spreads differently. Shells of low H/B exhibit plasticity at the quarter points, forming four plastic hinges, whereas this extends more widely in shells of high H/B. 


\section{Ultimate Dynamic Behaviour}

\subsection{Numerical Procedures}

This section examines the plastic mechanisms and ultimate failure conditions that the shells exhibit, using the results of nonlinear inelastic time history analysis through OpenSees [42]. Incremental dynamic analysis (IDA) [44] was employed for this purpose, using the seven records described in Section 3.4, as well as an additional seven records, as described in Table 6. The same shells used in previous sections were subjected to the fourteen records, applied in the X-direction. Each shell was subjected to at least twelve runs for each record, using the hunt and fill algorithm [45], increasing the intensity gradually until collapse was reached. Once again, force-based beam column elements were used, with different levels of element discretisation depending on the level of nonlinearity expected. The most detailed models used four elements per member, with five Gauss-Lobatto integration points per element.

The results of the IDA are shown in Figure 13 for five representative H/B values, using the peak angle change as the damage measure. The peak ground acceleration was used as the intensity measure as it was found to provide less dispersion than the first mode spectral acceleration. The median from the fourteen records, along with the 16 and 84 percentiles are also included.

The plots show that shells of high $\mathrm{H} / \mathrm{B}$ undergo comparatively higher levels of overall deformation at collapse than shells of lower $\mathrm{H} / \mathrm{B}$, but at lower levels of intensity. Higher levels of peak angle change are reached in shells of higher $\mathrm{H} / \mathrm{B}$, as, due to their geometry, their angles have more space to undergo larger changes in shape than those in shallower shells. The values of PGA at which collapse was reached are also dominated by H/B, as shells of low rise to span ratio sustain much higher intensities before collapse than their high rise to span ratio counterparts. Once again, their geometry allows them to resist horizontal forces in a more axially dominated manner, compared to shells of high $\mathrm{H} / \mathrm{B}$ which experience large bending moments that ultimately lead to earlier collapse.

\subsection{Location and Spread of Plasticity}

In addition to providing information on the global response, the IDA can be used to evaluate local demands, and help characterise the failure mechanisms of the shells. The values of the individual angle changes can be monitored as the loading progresses to capture the location and progression of damage. This supports the identification of critical regions and associated demand levels with respect to $\mathrm{H} / \mathrm{B}$ and increasing intensity. 
In order to characterise the failure mechanisms, and to account for the reversed cyclic nature of seismic loading, the angles are grouped in symmetrical pairs, as shown in Figure 14. Four different locations for damage are identified, corresponding to the pairs of angles $\theta_{1} / \theta_{7}, \theta_{2} / \theta_{6}$, $\theta_{3} / \theta_{5}$, and the central angle, $\theta_{4}$. In an analysis, if angle $\theta_{1}$ shows the highest angle change, for example, then $\theta_{7}$ would experience the same level of damage if the loading were applied in the opposite direction. Using the results from the IDAs, each individual angle change was measured. The maximum between each pairs of angles described in Figure 14 was determined for each record. The medians of these paired maximum angle changes were then obtained from the results of the fourteen records. These results are plotted against PGA in Figure 15 for five representative values of $\mathrm{H} / \mathrm{B}$.

From Figure 15, clear patterns can be observed when comparing shells of different H/B. The location of plastic hinges are the same as those identified from the pushover analysis described earlier, as depicted in Figure 12. A plastic hinge consistently occurs first at the quarter point (i.e. angle $\theta_{2} / \theta_{6}$ ), and then plasticity spreads to other locations depending on the specific geometry (i.e. H/B). This is also reflected in Figure 16 , in which $\theta_{2} / \theta_{6}$ exhibits maximum deformation at lower values of PGA, when plasticity is initiated. Once the first plastic hinge forms, plasticity spreads within the shells in different ways. In shells of low $\mathrm{H} / \mathrm{B}$, the deformation concentrates at the same quarter points, and hence the change in $\theta_{2} / \theta_{6}$ keeps increasing until collapse. In contrast, in shells of high $\mathrm{H} / \mathrm{B}$, the plasticity spreads to other areas, particularly at the first angle closest to the supports, i.e. $\theta_{1} / \theta_{7}$, which dominates the inelasticity at higher levels of PGA.

It is also interesting to observe the deformation in various angle pairs as collapse is initiated. Once the IDA begins to display a flat line, in shells of low $\mathrm{H} / \mathrm{B}$ the quarter point angle, i.e. $\theta_{2} / \theta_{6}$, dominates the response. Simultaneously, $\theta_{3} / \theta_{5}$ and the central angle $\theta_{4}$ exhibit large increases, although not the maximum values, whilst the change in angle $\theta_{1} / \theta_{7}$ remains relatively constant. This is indicative of snap-through behaviour, where the centre of the shell changes from convex to concave, producing large changes in the central and adjacent angles. This is particularly evident in Figure 17(a), which shows an example of the deformed shape at collapse from a typical record, for the shell of $\mathrm{H} / \mathrm{B}=0.1$. It can be observed that angles $\theta_{1}$ and $\theta_{7}$ experience the least deformation. It is also clear that the shell has snapped through and, consequently, the central angle $\theta_{4}$, has opened up considerably. These general patterns are captured in the plots of median individual angle changes in Figure 15.

As expected, the snap-through behaviour does not take place in shells of high $\mathrm{H} / \mathrm{B}$, where sway collapse occurs in a similar manner to a single storey frame. The first and last members are almost vertical in the initial geometry and thus act as columns, and plasticity is concentrated at their top. Thus, as the shell topples over, large deformations can be observed in $\theta_{1} / \theta_{7}$. In this case, the central portion of the shell experiences less damage, with $\theta_{4}$, 
undergoing little change, as illustrated in Figure 17(b) for $\mathrm{H} / \mathrm{B}=0.5$. Comparing Figures $17 \mathrm{a}$ and $b$, the reason for the larger deformations in shells of high $\mathrm{H} / \mathrm{B}$ becomes evident, as the changes in angles and displacements are of much higher magnitude. Aside from this, in this representative example, angle $\theta_{7}$ experiences a large change at collapse whereas, contrary to the shallow shell, the central angle, $\theta_{4}$, remains virtually unchanged at collapse.

\subsection{Possible Optimisation Strategies}

The above characterisation of typical plastic mechanisms provides useful insights into possible approaches that can be followed for optimising the distribution of cross-section sizes throughout the shell. Alternatively, this information can be used for selective local member reinforcement to improve the overall seismic performance. Understanding the location and spread of plasticity can inform size optimisation strategies in order to mitigate damage, reduce inelasticity, or prevent collapse, depending on the performance objective targeted.

In shells of low $\mathrm{H} / \mathrm{B}$, reinforcing the joint regions at angles $\theta_{2} / \theta_{6}$ would strengthen the shells and delay the onset of plasticity. Alternatively, if energy dissipation is required in areas of high seismicity, strengthening the central region at angle $\theta_{4}$ would lead to hinges forming at $\theta_{2} / \theta_{6}$. The strengthened central area could then resist snap-through, potentially preventing such mechanism. Another possibility would be to reinforce both regions of $\theta_{2}$ and $\theta_{6}$, in order to localise the damage at the central angle, $\theta_{4}$, hence creating a three hinged arch. Conversely, shells of high $\mathrm{H} / \mathrm{B}$ would benefit from a reinforcement of the joint regions for members at the location of angles $\theta_{1} / \theta_{7}$, which would encourage more plasticity at the $\theta_{2} / \theta_{6}$ location. These shells have relatively high redistribution potential, and such reinforcement could hence provide higher deformation capacity. It is also important to note that the deformations shown correspond to the edge arches of the shell, where the highest stresses occur. Accordingly, another possible strategy would be to strengthen the edge arches, hence encouraging the spread of plasticity throughout the entire shell, and potentially dissipating more energy by forming plastic hinges in more members before a mechanism is initiated.

Based on the observed plastic mechanisms, the above discussions suggest possible optimisation approaches for efficiently improving the seismic performance of the shells, through selective changes in member sizes. These concepts would require validation through detailed parametric and quantitative assessments in order to provide information suitable for direct application in design. 


\section{Performance Based Approaches}

\subsection{Existing Guidelines}

Performance based seismic design involves the stipulation of performance levels and associated objectives corresponding to specific seismic hazard scenarios, to provide better control on structural damage, life safety and economic losses [e.g. 46]. Based on the selected performance levels, the design is carried out such that these levels comply with the accepted probability of exceedance required for the specific seismic hazard considered.

In European seismic codes, specified limit states reflect increasing levels of structural damage, thus defining the performance at each stage. In Eurocode 8 Part 3 [47], for example, the following three limit states are suggested for building structures, in order of severity: Damage Limitation (DL), Significant Damage (SD), and Near Collapse (NC). Similar performance levels or limit states are also used in US guidelines, such as FEMA P-58 [48] and FEMA 350 [46]. Broadly equivalent limit states to those in Eurocode 8 are used, referred to as Immediate Occupancy, Life Safety, and Collapse Prevention. In FEMA 350, intended for the design of steel moment frames, the performance levels are linked to maximum levels of inter-storey drift, $\theta_{\max }$, as a representative predictor of damage in building structures.

\subsection{Proposed Procedures for Shell Structures}

Given the specific nature of shell structures, in terms of overall geometry as well as global and member deformations, it follows that similar indicators could be produced using the better suited peak angle change as a damage measure. In order to determine the appropriate levels of peak angle change corresponding to each limit state, the results from the incremental dynamic analyses were considered.

Various limiting conditions were used to produce indicators of damage that can be correlated with levels of peak angle change and, ultimately, performance levels. In the first instance, the IDA results were examined to determine the lowest intensity level that produced yielding, as defined in Equation (7), in one of the edge arch members. This first yielding correlates well with the limit state of 'Damage Limitation', as yielding is still not widespread, and the structure does not exhibit significant permanent deformation. For the performance level of 'Significant Damage', the first time a member reaches a rotation of $\mathrm{R}=6$, corresponding to the $6.0 \theta_{\mathrm{y}}$ rotation level, is used as suggested in Eurocode 8. Rotation is defined as $\mathrm{R}=\kappa / \kappa_{\mathrm{p}}$ 1 , where $\kappa$ is the curvature and $\kappa_{\mathrm{p}}$ is the curvature corresponding to the plastic moment capacity, expressed as $\kappa_{\mathrm{p}}=\mathrm{M}_{\mathrm{pl}} / \mathrm{EI}$, where $\mathrm{M}_{\mathrm{pl}}=\mathrm{W}_{\mathrm{pl}} \cdot \mathrm{f}_{\mathrm{y}}$, as defined in multiple studies [49-51].

In addition to the yielding and rotations in the members, the strain levels were also examined, in order to determine the points at which the critical strain, $\varepsilon_{\mathrm{cr}}$, is first reached in a member, 
as an indicator of local buckling. For circular hollow sections, the critical strain can be derived from the following expression [52]:

$$
\varepsilon_{c r}=\frac{\varepsilon_{y}}{f_{y}} \cdot \frac{E}{\sqrt{3\left(1-v^{2}\right)}} \cdot \frac{2 t}{D}
$$

This critical strain is dependent on the cross-section classification. For circular hollow sections, Table 5.2 of Eurocode 3 [39] defines a limit of $d / t \leq 50 \varepsilon^{2}$ for Class 1 cross-sections, and a limit of $d / t \leq 70 \varepsilon^{2}$ for Class 2 cross-sections, where $\varepsilon$ is defined as $\left(235 / f_{y}\right)^{1 / 2}$. To account for this, and to provide more generic design recommendations, the critical strain was derived for cross-sections with $\mathrm{d} / \mathrm{t}$ ratios at the limits of Class 1 and 2. Using Equation (8), a critical strain of $28.3 \%$ was obtained as the limit for Class 1, and 20.2\%o for Class 2 crosssections. These indicate when the critical strain is reached in members of the edge arches, thus identifying this limit condition for the two cross-section classifications.

These limit conditions are shown for five representative $\mathrm{H} / \mathrm{B}$ in Figure 18 , in which the different limit points are marked for each individual record as dots on the IDA curves. As these curves are an interpolation of a discrete number of analyses per record, the dots overlap at times for certain limit conditions that occur for the first time at the same intensity for a given record. The median value of each limit condition is presented in the plots as a vertical straight dashed line at the corresponding level of peak angle change.

The limit values of peak angle change obtained from the IDA are compared in Figure 19 with those obtained from the pushover analyses. Again, the strains corresponding to the limits for Class 1 and Class 2 cross-sections were used to assess the level at which the critical strain is reached. In the figure, the median values for each limit state from the pushover analysis are shown as solid vertical lines at the corresponding levels of peak angle change, and compared with the median values from the IDA, shown in dashed vertical lines.

Figure 20 compares the results obtained in Figure 18 and Figure 19 for the range of H/B ratios considered. It shows generally good agreement between the two methods of analysis. In addition, there is a reasonably close correlation between the levels of peak angle change and the different limit conditions. The value of critical strain for Class 1 sections in shells below $\mathrm{H} / \mathrm{B}=0.15$ was not reached in the pushover analysis, as the shells snap-through before excessive strains are attained since it rotates via the pinned supports. For this reason, the value obtained from IDA is omitted from the figure for consistency and clarity.

Based on the above discussion, values of peak angle change can be suggested as limits for performance levels. A value of peak angle change of 0.05 corresponds conservatively to the Damage Limitation level, which is associated with first yield in this case. The Significant Damage level can be represented by a peak angle change of 0.10 . This corresponds to limited plastic deformations. Finally, Near Collapse is associated with the type of cross section, as it is related to the onset of local buckling. For Class 2 cross-sections, a peak angle change of 
0.14 represents Near Collapse. Class 1 cross-sections, being more ductile, accommodate larger deformations before the critical strain is reached. Hence, the peak angle change value associated with Near Collapse for these cross-sections is set conservatively at 0.19 . The suggested performance levels are summarised in Table 7.

\section{Force and Displacement Modification Factors}

\subsection{Behaviour Factors}

Simplified design procedures adopted in seismic codes for regular structural configurations are based on elastic analysis, in conjunction with force and displacement modification factors that account, in an approximate manner, for inelastic response [53]. This section examines representative ranges that can be used for shell structures to enable implementation of current codified approaches to this structural form. Behaviour factors, which are also referred to as response modification or force reduction factors, are commonly used in simplified seismic design practice for typical structures. They allow a reduction of the design lateral force applied in a linear analysis, to account for the nonlinear inelastic effects based on the level of ductility and overstrength, as studied extensively in previous research [54, 55].

There are several definitions and approaches for determining the behaviour factor, $\mathrm{q}$. The draft revision of Eurocode 8 [43], which is currently under development, defines q in a clear manner as the product of three components: (i) $q_{R}$, which accounts for the overstrength due to the redistribution of seismic action effects in redundant structures (referred to as $\alpha_{\mathrm{u}} / \alpha_{1}$ in current provisions), (ii) $\mathrm{q}_{\mathrm{D}}$, which accounts for the ductility and energy dissipation capacity, and (iii) qs, which encompasses overstrength from all other sources, such as members being oversized due to standardised section sizes, requirements of other load combinations, as well as drift and stability considerations. The behaviour factor component related to redistribution, $\mathrm{q}_{\mathrm{R}}$, ranges between 1.20 and 1.32 for shell structures, as discussed in Section 4.2. Thus, an approximate value of 1.25 can be suggested for these structures. The component dealing with overstrength from other sources, $\mathrm{q}_{\mathrm{S}}$, is assigned a recommended value of 1.5 in the code. The deeper shells designed in this study used bespoke sections which were sized to fit exactly the strength requirements, for the purpose of keeping results as close as possible to their theoretical values. Accordingly, they do not exhibit notable overstrength from using standard circular hollow section sizes. In contrast, the shallower shells do have considerable overstrength arising from the fact that buckling against gravity loads governed their design rather than strength demands from seismic actions.

The 'actual' behaviour factor of the structure can be considered as that relating the acceleration at collapse to that at the actual recorded point of first yield. This differs from the 
design behaviour factors in codes of practice, which take into account the different sources of overstrength, and design levels of base shear. This actual behaviour factor depends on the definition of first yield, and is referred to as $\mathrm{q}_{\text {act }}$ herein. It is essentially equivalent to $\mathrm{q}_{\mathrm{R}} \times \mathrm{q}_{\mathrm{D}}$ as defined by codes, since it is evaluated considering the actual point of first yield. One of the commonly used methods for obtaining the behaviour factor involves the use of the acceleration ratio [56-58] as follows:

$$
q_{a c t}=\frac{a_{g(\text { collapse })}}{a_{g(\text { yield })}}
$$

This defines the actual behaviour factor as the ratio between the peak ground acceleration leading to collapse versus that corresponding to first yield. Using the different definitions for collapse, and with reference to Figure 18, different behaviour factors can be determined. Five cases are considered herein for collapse: (i) Near Collapse limit state for Class 1 is reached (as defined in Table 7), (ii) Near Collapse limit state for Class 2 is reached, (iii) critical strain is reached for Class 1, (iv) critical strain is reached for Class 2, and (v) peak ground acceleration corresponding to flattening of IDA curves (i.e. the last recorded run of the IDA, labelled 'IDA limit'). The results are collated in Figure 21 where, as expected, it is shown that the behaviour factors derived using the global collapse (i.e. flattening of IDA curves) give the highest values, ranging from 3.6 to 5.9. Values for Class 2 are between 2.0 and 2.8, whilst those for Class 1 vary between 2.7 and 3.6, depending on $\mathrm{H} / \mathrm{B}$. These values are close to the NC limit state for each corresponding cross-section class, as expected, as the performance level was set based on the peak angle change corresponding to the critical strain. It should also be noted that serviceability requirements could also limit the level of deformations for shells of high $\mathrm{H} / \mathrm{B}$ ratios, as they tend to be comparatively flexible.

Based on the above results and discussions, a recommended conservative value of behaviour factor for such shells would be $\mathrm{q}_{\text {act }}=2.0$ for Class 2 cross-sections, and $\mathrm{q}_{\text {act }}=2.7$ for shells employing Class 1 cross-sections. These values are obtained as the minimum value for the entire range of $\mathrm{H} / \mathrm{B}$, rounded up to the nearest 0.1 , and are also marked on Figure 21 for reference. It is also worth noting that the design behaviour factor, which would include qs of at least 1.5 to account for overstrength, would lead to values of q of about 3.0 and 4.0. These represent the upper bound of behaviour factors that could be used in design. However, given the large PGA values needed to reach such high inelasticity levels, it is unlikely that the use of such upper bound values would be practical or necessary.

\subsection{Displacement Modification Factors}

In addition to behaviour factors, which deal with the reduction of applied forces for seismic design, modification factors are also required in order to estimate inelastic demands from those obtained from linear elastic analysis $[59,60]$. In a similar fashion to behaviour factors, 
displacement modification factors relate the maximum expected level of drift or deformation to that measured at first yield. In order to relate these two quantities, the intensity factor, q', is introduced, acting as a multiple of the base shear experienced by the structure at first yield $\left(\mathrm{V}_{1}\right)$, and obtained using the scaling factor (SF) for each record in each individual time history run from the IDA, as follows [59]:

$$
q^{\prime}=S F \cdot \frac{S_{a}\left(T_{1}\right) \cdot m \cdot \gamma_{1}}{V_{1}}
$$

Accordingly, the following modification factors are presented, for peak angle change and drift, respectively:

$$
\begin{aligned}
\Delta \theta_{\text {max }, \text { mod }} & =\frac{\Delta_{\theta \max , \max }}{q^{\prime} \cdot \Delta_{\theta \max , 1}} \\
\delta_{\text {mod }} & =\frac{\delta_{\max }}{q^{\prime} \cdot \delta_{1}}
\end{aligned}
$$

The values of peak angle change and drift at first yield are as obtained from the pushover analyses, as given in Table 5. The maximum values are obtained from IDA, at each respective level of intensity. Values were calculated at inelasticity levels of $q^{\prime}=1$ to $q^{\prime}=4$, capturing the possible range of intensities for these structures, considering the medians of values extracted from each of the fourteen records. The influence of $\mathrm{H} / \mathrm{B}$ and $\mathrm{q}^{\prime}$ on the modification factors is depicted in Figure 22 for the peak angle change (a), and drift (b). The coefficients of variation for each of these factors are also presented in Figure 23.

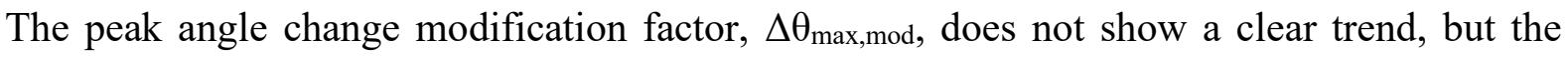
values are consistent around a specific range, with an average value of around 0.7 . In this case, $\mathrm{H} / \mathrm{B}$ does not seem to play a notable role, except for a small increase around $\mathrm{H} / \mathrm{B}=0.3$. Considering the coefficients of variation in Figure 23 (a), a large scatter is observed in the results, especially for values of $q^{\prime}=4$. In the absence of clear trends, the equal displacement rule could be applied conservatively. This would mean a value of $\Delta \theta_{\max \text {,mod }}=1.0$ for simplified design purposes for values of q' below 4 .

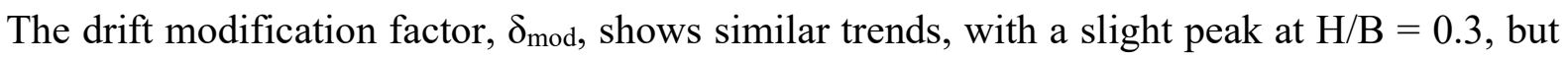
remaining fairly constant, at an average value of around 0.6 . For the drift, as q' increases, $\delta_{\text {mod }}$ decreases. This is because, initially, the top node can experience relatively large horizontal displacements under seismic actions. As the loading and deformations increase, the displacement of the top node starts becoming more vertical, as it follows the geometry of the shell. Since the horizontal displacements are not increasing as much, the drift does not increase accordingly. This is in contrast to high $\mathrm{H} / \mathrm{B}$, where for very high levels of loading the shell topples over at collapse, as opposed to snapping through for shallow shells, which again leads to a large increase in horizontal displacement. 
Considering the $\mathrm{CoV}$ values for $\delta_{\text {mod }}$ in Figure 23 (b), lower values are obtained compared to

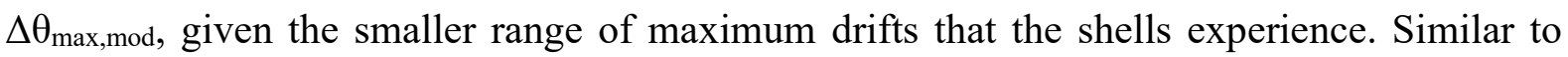
$\Delta \theta_{\text {max,mod, }}$ it would be recommended for simplified design to adopt the equal displacement rule, as this conservative approach is already typically followed in current European seismic design codes. This limit is marked on Figure 22 for reference, and is consistent with results obtained in recent studies by Khalili et al. [30] for other shell configurations.

\subsection{Simplified Inelastic Design Procedure}

The use of pushover and time history analysis in practice tends to be selective, and is reserved more for verification or assessment purposes rather than initial design. For structures of significant importance, a simplified analysis might be carried out first, and then a more detailed verification would take place using more sophisticated methods of analysis, like performance based approaches with nonlinear time history analysis. The above assessments and discussions provide information and parameters that can be used for simplified inelastic seismic design of single layer steel shells. A proposed simplified design procedure for areas of high seismicity would involve the following steps:

1. Obtain the dynamic characteristics of the structure and corresponding seismic forces using the procedure outlined in Section 3.5

2. Use a behaviour factor within the values recommended in Section 7.1 to reduce the forces by dividing the demand by the chosen value of $\mathrm{q}$.

3. Use the equal displacement rule suggested in Section 7.3 to estimate the expected level of inelastic deformation that the shell structure will undergo.

4. Check if the estimated peak angle change meets the relevant performance limits proposed in Table 7.

5. Design members accordingly to meet the required force and displacement demands.

As with any design process, a level of iteration might be required to obtain the desired performance. The use of pushover analysis can improve the accuracy of the first step by providing a more precise estimate of the level of forces and deformation at first yield. Once a satisfactory design is achieved, for structures of high importance, incremental dynamic analysis, as described in Section 5, can be used as an assessment tool to validate the chosen design with a higher degree of detail.

\section{Concluding Remarks}

This paper examined practical aspects and subsequently proposed guidance, which is currently largely lacking, for the seismic design of single layer cylindrical lattice shells. The results from a number of investigations, including linear and nonlinear numerical assessments, were used in order to provide detailed insights into the seismic performance and to suggest suitable procedures for practical application. 
An initial insight into the relative influence of seismic loading on shell design, in comparison to gravity conditions, was firstly provided through the use of digital parametric engineering procedures. It was shown that that a horizontal seismic excitation of $0.20 \mathrm{~g}$ would generally govern member sizes in design over gravity loads, particularly for shells with H/B higher than 0.20 . For shallower shells, gravity loads and buckling typically governed the design.

Supported by the results of elastic seismic assessments, together with prediction expressions for dynamic characteristics, a simplified procedure was proposed for estimating the internal seismic forces within the shells for the purpose of member sizing in early design stages. The estimates of maximum bending moments and axial forces obtained in the members compared generally well with those obtained from detailed elastic time history analyses.

Suitable approaches for nonlinear static, i.e. pushover, analysis were discussed, with focus on identifying the inherent plastic mechanisms. Suggestions were made for the most appropriate damage measure and point of first yield specific to shell structures. The overstrength due to redistribution was found to be between 1.20 and 1.32, with a typical average of 1.25.

The results of incremental nonlinear dynamic analysis were also employed in order to validate the findings and to further assess the ultimate response under realistic seismic loading conditions. The plastic mechanisms of the shells were explored and characterised from the dynamic response, by determining the individual angle changes in the edge arch. The areas experiencing concentrated plasticity were identified, with distinct differences observed between shallow and deep shells. Having identified the failure mechanisms of the shells, possible optimisation approaches which could be used to improve their performance were suggested.

Based on the incremental dynamic analysis results, coupled with the findings from the pushover assessments, representative ranges for behaviour factors and displacement modification coefficients were derived alongside discussions on their implementation within codified seismic design procedures. Apart from providing recommendations for simplified design approaches, the assessments presented in this paper can also be used to support detailed performance based guidelines as well as for informing geometry and size optimisation strategies.

The discussions and procedures described in this paper could also be extended, with the support of specific verification studies, to shells of other geometries and configurations. Measuring damage through peak angle change could also be useful for other types of freeform surface grid structures, since it can be applied to any geometry formed by angled members, as is the case in any structure following a curved surface. Similarly, the limits proposed for performance based design could serve as a starting point for the seismic design of any type of lattice shell structure.

\section{Acknowledgements}

The first author acknowledges the studentship support provided by the UK Engineering and Physical Sciences Research Council. 


\section{References}

1. Forman, S.E. and J.W. Hutchinson, Buckling of reticulated shell structures. International Journal of Solids and Structures, 1970. 6(7): p. 909-932.

2. Kokawa, T., General Buckling of Cylindrical Reticulated Shell Roofs with Arbitrary Generator Edges. Journal of Structural and Construction Engineering, Architectural Institute of Japan, 1979: p. 76-86.

3. Mahadevappa, P., N. Subramanian, and L.N. Ramamurthy, A study on the behaviour of steel braced barrel vaults. Building and Environment, 1980. 15: p. 191-195.

4. Kollár, L. and E. Dulácksa, Buckling of Shells for Engineers. 1984, New York: John Wiley \& Sons.

5. Makowski, Z.S., ed. Analysis, design and construction of braced barrel vaults. 1985, Elsevier Applied Science Publishers: London.

6. Gioncu, V., Buckling of reticulated shells, state of the art. International Journal of Space Structures, 1995. 10(1): p. 1-46.

7. El-Sheikh, A., Performance of single-layer barrel vaults with different configurations. International Journal of Space Structures, 2001. 16(2): p. 111-123.

8. Hanaor, A., Design and behaviour of reticulated spatial structural systems. International Journal of Space Structures, 2011. 26(3): p. 193-203.

9. Kato, S., Guide to Buckling Load Evaluation of Metal Reticulated Roof Structures. 2014: IASS Working Group 8.

10. Kato, S., T. Yamashita, S. Nakazawa, Y.-b. Kim, and A. Fujibayashi, Analysis based evaluation for buckling loads of two-way elliptic paraboloidal single layer lattice domes. Journal of Constructional Steel Research, 2007. 63(9): p. 1219-1227.

11. Kato, S. and T. Yamashita, Evaluation of buckling load of two-way single layer grid shells. Journal of the International Association for Shell and Spatial Structures, 2010. 51(2): p. 109123.

12. Ishikawa, K. and S. Kato, Elastic-plastic dynamic buckling analysis of reticular domes subjected to earthquake motion. International Journal of Space Structures, 1997. 12(3\&4): p. 205-215.

13. Malek, S., T. Wierzbicki, and J. Ochsendorf, Buckling of spherical cap gridshells: A numerical and analytical study revisiting the concept of the equivalent continuum. Engineering Structures, 2014. 75: p. 288-298.

14. Dulácksa, E. and L. Kollár, Buckling analysis of reticulated shells. International Journal of Space Structures, 2000. 15(3): p. 195-203.

15. Bulenda, T. and J. Knippers, Stability of grid shells. Computers and Structures, 2001. 79: p. 1161-1174.

16. Cao, Z.G., F. Fan, Y. Sun, and H.H. Ma. Elasto-plastic stability of single-layer cylindrical reticulated shells. in International Association for Shell and Spatial Structures (IASS) Symposium 2009. 2009. Universidad Politécnica de Valencia, Valencia, Spain.

17. Yamada, S., Buckling load evaluation method for single layer cylindrical lattice shells. Journal of Civil Engineering and Architecture, 2012. 6(3): p. 268.

18. Mohammadi, M., K. Abedi, and N. Taghizadieh, Stability analysis of single-layer barrel vault space structures. International Journal of Space Structures, 2012. 27(4): p. 203-218.

19. He, Y., X. Zhou, and D. Liu, Research on stability of single-layer inverted catenary cylindrical reticulated shells. Thin-Walled Structures, 2014. 82: p. 233-244.

20. Saka, T. and Y. Taniguchi, Damage to spatial structures by the 1995 Hyogoken-Nanbu earthquake in Japan. International Journal of Space Structures, 1997. 12(3\&4): p. 125-133. 
21. Qi, L., Y. Shao, Z. Huang, and X. Huang, Dynamic damage criterion and damage mode for single layer lattice shell. Journal of Constructional Steel Research, 2014. 99: p. 102-110.

22. Shen, C., C. Huang, and Y. Gao, Seismic analysis of the single-layered cylindrical grid shell. Applied Mechanics and Materials, 2012. 166-169: p. 2159-2163.

23. Zhi, X.-D., F. Fan, and S.-Z. Shen, Failure mechanism of single-layer cylindrical reticulated shells under earthquake motion. International Journal of Structural Stability and Dynamics, 2012. 12(02): p. 233-249.

24. Ma, H.F., Feng; Wen, Peng; Zhang, Hao; Shen, Shizhao, Experimental and numerical studies on a single-layer cylindrical reticulated shell with semi-rigid joints. Thin-Walled Structures, 2015. 86: p. 1-9.

25. Ma, H., Z. Shan, and F. Fan, Dynamic behaviour and seismic design method of a single-layer reticulated shell with semi-rigid joints. Thin-Walled Structures, 2017. 119: p. 544-557.

26. Shin, J.L., Kihak; Kim, Gee-Cheol; Jung, Chan-Woo; Kang, Joo-Won, Analytical and experimental studies on seismic behavior of double-layer barrel vault systems with different open angles. Thin-Walled Structures, 2012. 54: p. 113-125.

27. Takeuchi, T., T. Ogawa, and T. Kumagai, Seismic response evaluation of lattice shell roofs using amplification factors. Journal of the International Association for Shell and Spatial Structures, 2007. 48(3): p. 197-210.

28. Shen, S., J. Xing, and F. Fan, Dynamic behavior of single-layer latticed cylindrical shells subjected to seismic loading. Earthquake Engineering and Engineering Vibration, 2003. 2(2): p. 269-279.

29. Chen, Y.B., Q.S. Li, and J.M. Chen, Dynamic characteristics of single-layer cylindrical lattice shells. Proceedings of the ICE - Structures and Buildings, 2005. 158(1): p. 41-51.

30. Khalili, R., M. Poursha, and K. Abedi, Behavior factor and displacement amplification factor for the seismic design of single-layer barrel vaults. Journal of Constructional Steel Research, 2020. 169: p. 105987.

31. Nakazawa, S.K., Shiro; Takeuchi, Toru; Xue, Su-Duo; Lazaro, Carlos, State-of-the-art of seismic response evaluation methods for metal roof spatial structures. Journal-International Association for Shell and Spatial Structures, 2012. 53(2): p. 117-130.

32. IASS Working Group 8, Guide to Earthquake Response Evaluation of Metal Roof Spatial Structures. 2019: International Association for Shell and Spatial Structures (IASS).

33. CEN, BS EN 1998-1-2004+A1-2013 Eurocode 8: Design of structures for earthquake resistance, in Part 1: General rules, seismic actions and rules for buildings. 2004, British Standards Institution.

34. Cedrón, F. and A.Y. Elghazouli, Seismic performance of single layer steel cylindrical lattice shells. Journal of Constructional Steel Research, 2019. 163: p. 105772.

35. Parke, G.A.R., Comparison of the Structural Behaviour of Various Types of Braced Barrel Vaults, in Analysis, Design, and Construction of Braced Barrel Vaults, Z.S. Makowski, Editor. 1985, Elsevier Applied Science Publishers: London and New York. p. 113-144.

36. Preisinger, C. karamba 3d. 2016 [cited 2016 March]; Available from: http://www.karamba3d.com/.

37. Rutten, D., Grasshopper. 2007, Robert McNeel \& Associates.

38. Robert McNeel \& Associates, Rhinoceros. 2018.

39. CEN, BS EN 1993-1-1:2005+A1:2014 Eurocode 3: Design of steel structures, in Part 1.1: General rules and rules for buildings. 2005, British Standards Institution.

40. CSI, SAP2000 Integrated Software for Structural Analysis and Design. 2018, Computers and Structures Inc.: Berkeley, California. 
41. Sadeghi, A., Assessing the simultaneous effects of horizontal and vertical components of earthquakes on the double layer barrel vaults, in Progress of Geo-Disaster Mitigation Technology in Asia, F.W.e. al., Editor. 2013, Springer-Verlag: Berlin. p. 331-347.

42. McKenna, F. Open System for Earthquake Engineering Simulation. 2006 [cited 2016; Available from: http://opensees.berkeley.edu/.

43. CEN, Final Draft EN1998-1-2 NEN SC8 PT2 Eurocode 8: - Design of structures for earthquake resistance - Part 1-2:Rules for new buildings. 2019, CEN.

44. Vamvatsikos, D. and C.A. Cornell, Incremental dynamic analysis. Earthquake Engineering and Structural Dynamics, 2002(31): p. 491-514.

45. Vamvatsikos, D. and C.A. Cornell, Applied incremental dynamic analysis. Earthquake Spectra, 2004. 20(2): p. 523-553.

46. Applied Technology Council, FEMA P-58 Seismic performance assessment of buildings, FEMA, Editor. 2012: Washington, D.C.

47. CEN, BS EN 1998-3-2005 Eurocode 8: Design of structures for earthquake resistance, in Part 3: Assessment and retrofitting of buildings. 2005, British Standards Institution.

48. SAC Joint Venture, FEMA 350 Recommended Seismic Design Criteria for New Steel Moment-Frame Buildings. 2000, Federal Emergency Management Agency: Washington D.C.

49. Elchalakani, M., X.L. Zhao, and R. Grzebieta, Bending tests to determine slenderness limits for cold-formed circular hollow sections. Journal of Constructional Steel Research, 2002. 58: p. $1407-1430$.

50. Jiao, H. and X.L. Zhao, Section slenderness limits of very high strength circular steel tubes in bending. Thin-Walled Structures, 2004. 42(9): p. 1257-1271.

51. Elchalakani, M., X.L. Zhao, and R.H. Grzebieta, Plastic Slenderness Limits for Cold-Formed Circular Hollow Sections. Australian Journal of Structural Engineering, 2015. 3(3): p. 127141.

52. Buchanan, C., L. Gardner, and A. Liew, The continuous strength method for the design of circular hollow sections. Journal of Constructional Steel Research, 2016. 118: p. 207-216.

53. Elghazouli, A.Y., ed. Seismic Design of Buildings to Eurocode 8. 2nd ed. 2017, Taylor and Francis.

54. Fathi, M., F. Daneshjoo, and R.E. Melchers, A method for determining the behaviour factor of moment-resisting steel frames with semi-rigid connections. Engineering Structures, 2006. 28(4): p. 514-531.

55. Elghazouli, A.Y., Assessment of European seismic design procedures for steel framed structures. Bulletin of Earthquake Engineering, 2009. 8(1): p. 65-89.

56. Elnashai, A.S., B.M. Broderick, and L.M. Salvitti, Assessment of EC8 behaviour factors for $R C$, steel and composite frames, in Eleventh World Conference on Earthquake Engineering. 1996.

57. Kappos, A.J., Evaluation of behaviour factors on the basis of ductility and overstrength studies. Engineering Structures, 1999. 21: p. 823-835.

58. Castiglioni, C.A. and A. Zambrano, Determination of the behaviour factor of steel momentresisting (MR) frames by a damage accumulation approach. Journal of Constructional Steel Research, 2010. 66(5): p. 723-735.

59. Kumar, M., P.J. Stafford, and A.Y. Elghazouli, Influence of ground motion characteristics on drift demands in steel moment frames designed to Eurocode 8. Engineering Structures, 2013. 52: p. 502-517.

60. Kumar, M., P.J. Stafford, and A.Y. Elghazouli, Seismic shear demands in multi-storey steel frames designed to Eurocode 8. Engineering Structures, 2013. 52: p. 69-87. 


\section{List of notations}

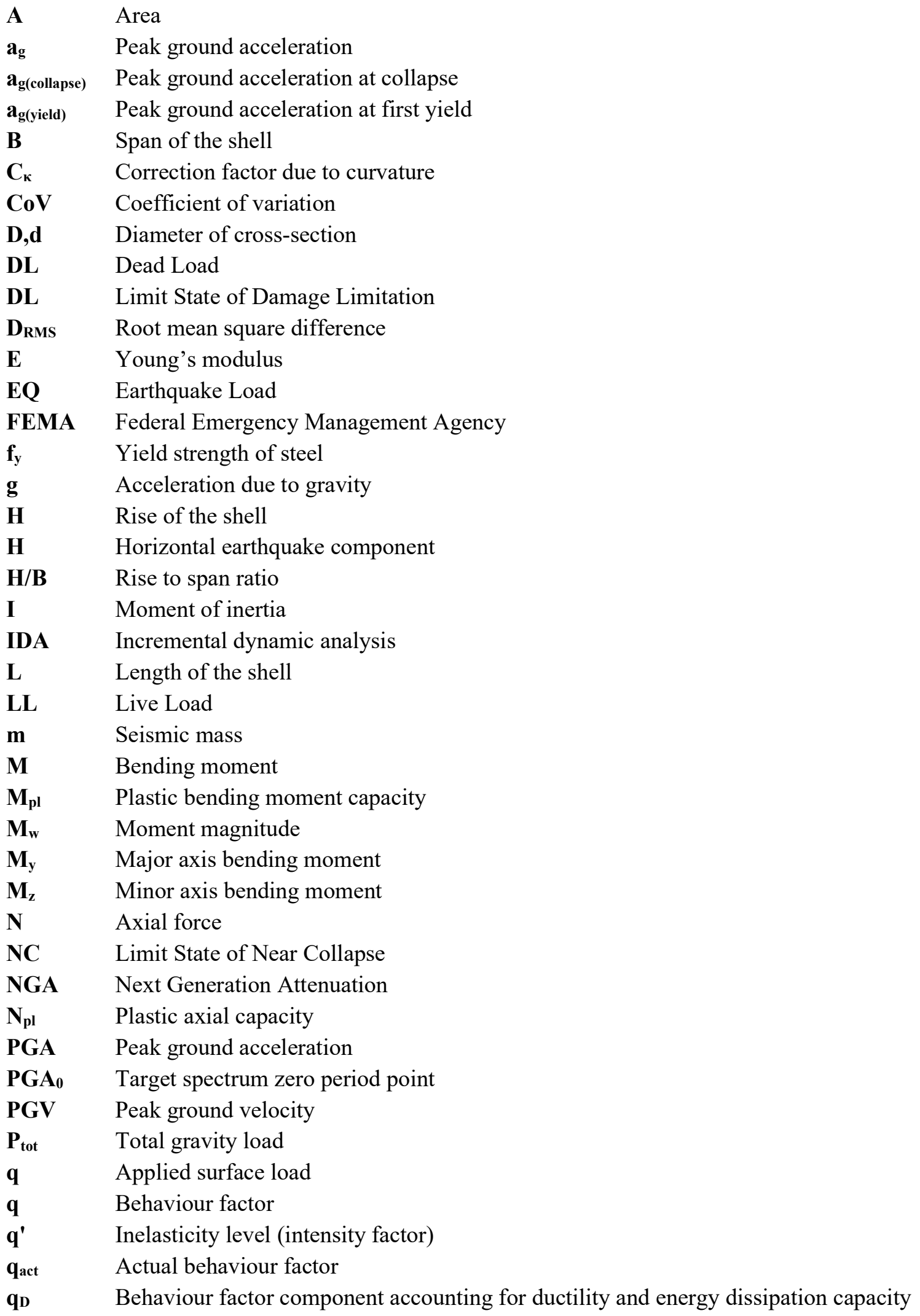




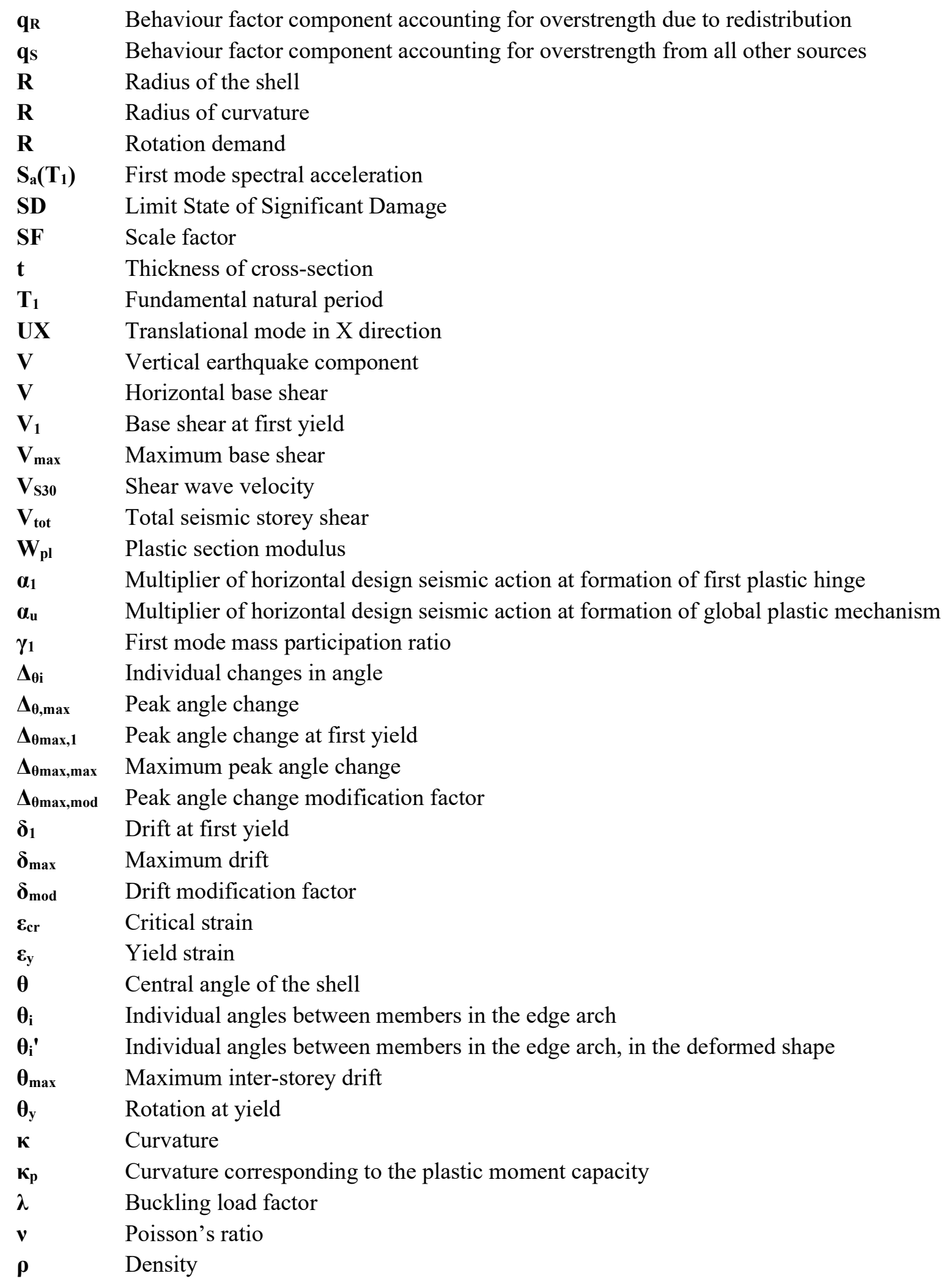




\section{Tables}

Table 1: Shell dynamic and design characteristics and member sizes

\begin{tabular}{lccccccccc}
\hline Rise to Span Ratio, H/B & $\mathbf{0 . 1 0}$ & $\mathbf{0 . 1 5}$ & $\mathbf{0 . 2 0}$ & $\mathbf{0 . 2 5}$ & $\mathbf{0 . 3 0}$ & $\mathbf{0 . 3 5}$ & $\mathbf{0 . 4 0}$ & $\mathbf{0 . 4 5}$ & $\mathbf{0 . 5 0}$ \\
\hline Height, h (m) & 1.50 & 2.25 & 3.00 & 3.75 & 4.50 & 5.25 & 6.00 & 6.75 & 7.50 \\
Longitudinals, D $\times$ t (mm) & $60 \times 4$ & $60 \times 4$ & $60 \times 4$ & $60 \times 4$ & $60 \times 4$ & $60 \times 4$ & $60 \times 4$ & $60 \times 4$ & $60 \times 4$ \\
Diagonals, D $\times$ t (mm) & $165 \times 4$ & $148 \times 4$ & $141 \times 4$ & $139 \times 4$ & $140 \times 4$ & $144 \times 4$ & $151 \times 4$ & $166 \times 4$ & $174 \times 4$ \\
$1^{\text {st }}$ Mode Period, $\mathrm{T}_{1}(\mathrm{~s})$ & 0.558 & 0.721 & 0.877 & 1.039 & 1.212 & 1.384 & 1.547 & 1.615 & 1.812 \\
$1^{\text {st }}$ Mode Mass & 0.122 & 0.249 & 0.389 & 0.523 & 0.640 & 0.735 & 0.808 & 0.862 & 0.900 \\
Participation Ratio & 1.03 & 1.01 & 1.03 & 1.04 & 1.03 & 1.02 & 1.03 & 1.27 & 1.14 \\
$\begin{array}{l}\text { Buckling Factor, } \lambda \\
\text { Maximum Utilisation Ratio }\end{array}$ & 0.422 & 0.555 & 0.666 & 0.773 & 0.872 & 0.952 & 1.000 & 0.993 & 0.993 \\
$\begin{array}{l}\text { Governing design aspect } \\
\text { Buckling (B)/Strength (S) }\end{array}$ & $\mathrm{B}$ & $\mathrm{B}$ & $\mathrm{B}$ & $\mathrm{B}$ & $\mathrm{B}$ & $\mathrm{B}$ & $\mathrm{S}$ & $\mathrm{S}$ & $\mathrm{S}$ \\
\hline
\end{tabular}

Table 2: Record selection used in time history analyses. ' $\mathrm{L}$ ' and ' $\mathrm{T}$ ' in the Record No. refer to 'Longitudinal' and 'Transverse' components of ground-motions, respectively

\begin{tabular}{|c|c|c|c|c|c|c|c|c|c|c|}
\hline $\begin{array}{c}\text { NGA } \\
\text { Record } \\
\text { No. }\end{array}$ & Earthquake Name & Date & $\begin{array}{c}\text { Magni- } \\
\text { tude } \\
M_{w}\end{array}$ & $\begin{array}{c}\text { Distance } \\
\text { to Fault } \\
(\mathbf{k m})\end{array}$ & $\begin{array}{l}V_{\mathrm{S} 30} \\
(\mathrm{~m} / \mathrm{s})\end{array}$ & $\begin{array}{c}\text { PGA } \\
\text { (g) }\end{array}$ & $\begin{array}{c}\text { PGV } \\
(\mathrm{cm} / \mathrm{s})\end{array}$ & $\begin{array}{l}\text { Scale } \\
\text { Factor }\end{array}$ & $\begin{array}{c}\text { Scaled } \\
\text { PGA }\end{array}$ & D RMS \\
\hline $00564 \mathrm{~L}$ & Kalamata, Greece & $13 / 09 / 86$ & 6.2 & 11.2 & 339 & 0.26 & 27.18 & 1.23 & 0.32 & 0.188 \\
\hline $00127 \mathrm{~T}$ & Friuli, Italy & $11 / 09 / 76$ & 5.5 & 15.1 & 339 & 0.05 & 4.86 & 7.55 & 0.38 & 0.197 \\
\hline 00299L & Irpinia, Italy & $23 / 11 / 80$ & 6.2 & 41.7 & 500 & 0.04 & 3.45 & 9.83 & 0.39 & 0.226 \\
\hline $00302 \mathrm{~T}$ & Irpinia, Italy & $23 / 11 / 80$ & 6.2 & 22.7 & 530 & 0.11 & 11.56 & 3.49 & 0.38 & 0.230 \\
\hline $01137 \mathrm{~T}$ & Dinar, Turkey & $01 / 10 / 95$ & 6.4 & 35.6 & 339 & 0.04 & 4.65 & 7.16 & 0.29 & 0.245 \\
\hline 00130L & Friuli, Italy & $15 / 09 / 76$ & 5.9 & 14.3 & 339 & 0.11 & 11.37 & 3.03 & 0.33 & 0.246 \\
\hline 00481L & Lazio-Abruzzo, Italy & $07 / 05 / 84$ & 5.8 & 45.5 & 339 & 0.04 & 3.55 & 9.25 & 0.37 & 0.254 \\
\hline
\end{tabular}

Table 3: Percentage difference between the average internal forces obtained from the prediction method and the time history analyses.

\begin{tabular}{rcccccccccc}
\hline Rise/Span (H/B) & $\mathbf{0 . 1 0}$ & $\mathbf{0 . 1 5}$ & $\mathbf{0 . 2 0}$ & $\mathbf{0 . 2 5}$ & $\mathbf{0 . 3 0}$ & $\mathbf{0 . 3 5}$ & $\mathbf{0 . 4 0}$ & $\mathbf{0 . 4 5}$ & $\mathbf{0 . 5 0}$ & Average \\
\hline Axial Forces & $-12 \%$ & $-16 \%$ & $-20 \%$ & $-18 \%$ & $-14 \%$ & $-13 \%$ & $-10 \%$ & $-6 \%$ & $-3 \%$ & $-12 \%$ \\
Bending Moment & $6 \%$ & $7 \%$ & $7 \%$ & $8 \%$ & $8 \%$ & $10 \%$ & $12 \%$ & $10 \%$ & $10 \%$ & $9 \%$ \\
\hline
\end{tabular}

Table 4: Percentage difference between the maximum internal forces obtained from the prediction method and the time history analyses

\begin{tabular}{rcccccccccc}
\hline Rise/Span (H/B) & $\mathbf{0 . 1 0}$ & $\mathbf{0 . 1 5}$ & $\mathbf{0 . 2 0}$ & $\mathbf{0 . 2 5}$ & $\mathbf{0 . 3 0}$ & $\mathbf{0 . 3 5}$ & $\mathbf{0 . 4 0}$ & $\mathbf{0 . 4 5}$ & $\mathbf{0 . 5 0}$ & Average \\
\hline Axial Forces & $-11 \%$ & $-13 \%$ & $-17 \%$ & $-10 \%$ & $-6 \%$ & $-5 \%$ & $-3 \%$ & $-4 \%$ & $-4 \%$ & $-8 \%$ \\
Bending Moment & $-4 \%$ & $-1 \%$ & $3 \%$ & $4 \%$ & $5 \%$ & $7 \%$ & $8 \%$ & $9 \%$ & $9 \%$ & $5 \%$ \\
\hline
\end{tabular}


Table 5: Summary of pushover analysis results

\begin{tabular}{|c|c|c|c|c|c|c|c|c|c|}
\hline Rise to Span Ratio, H/B & 0.10 & 0.15 & 0.20 & 0.25 & 0.30 & 0.35 & 0.40 & 0.45 & 0.50 \\
\hline Height, h (m) & 1.50 & 2.25 & 3.00 & 3.75 & 4.50 & 5.25 & 6.00 & 6.75 & 7.50 \\
\hline $\begin{array}{l}\text { Base Z Reaction, } P_{\text {tot }} \\
(\mathrm{kN})\end{array}$ & 542 & 545 & 571 & 590 & 630 & 660 & 711 & 753 & 815 \\
\hline $\begin{array}{l}\text { Max Base Shear, } V_{\max } \\
(\mathrm{kN})\end{array}$ & 263 & 281 & 290 & 289 & 279 & 269 & 262 & 293 & 265 \\
\hline \multicolumn{10}{|l|}{ At $1^{\text {st }}$ Yield: } \\
\hline Base shear, $V_{1}(\mathrm{kN})$ & 210 & 218 & 220 & 218 & 211 & 205 & 204 & 230 & 220 \\
\hline $\begin{array}{l}\text { Top Node X } \\
\text { Displacement (m) }\end{array}$ & 0.035 & 0.060 & 0.089 & 0.121 & 0.155 & 0.191 & 0.228 & 0.261 & 0.313 \\
\hline Top Node X Drift (\%) & 2.31 & 2.69 & 2.98 & 3.22 & 3.44 & 3.63 & 3.80 & 3.87 & 4.17 \\
\hline Peak Angle Change (rad) & 0.051 & 0.054 & 0.056 & 0.058 & 0.060 & 0.060 & 0.060 & 0.058 & 0.060 \\
\hline Peak R & 1.661 & 1.206 & 0.761 & 0.664 & 0.629 & 0.609 & 0.593 & 0.587 & 0.619 \\
\hline $\mathrm{V}_{\max } / \mathrm{V}_{1}$ & 1.25 & 1.29 & 1.32 & 1.33 & 1.32 & 131 & 1.28 & 1.27 & 1.20 \\
\hline
\end{tabular}

Table 6: Additional set of records used in the IDA

\begin{tabular}{cccccccc}
\hline $\begin{array}{c}\text { NGA } \\
\text { Record } \\
\text { No. }\end{array}$ & Earthquake Name & Date & $\begin{array}{c}\text { Magni- } \\
\text { tude } \\
\mathbf{M}_{\mathbf{w}}\end{array}$ & $\begin{array}{c}\text { Distance } \\
\text { to Fault } \\
\mathbf{( k m )}\end{array}$ & $\begin{array}{c}\mathbf{V}_{\mathbf{s 3 0}} \\
\mathbf{( m / s})\end{array}$ & $\begin{array}{c}\text { PGA } \\
\mathbf{( g )}\end{array}$ & $\begin{array}{c}\text { PGV } \\
(\mathbf{c m} / \mathbf{s})\end{array}$ \\
\hline 00293T & Irpinia, Italy & $23 / 11 / 1980$ & 6.9 & 59.6 & 660 & 0.05 & 7.89 \\
01163L & Kocaeli, Turkey & $17 / 08 / 1999$ & 7.5 & 58.3 & 425 & 0.09 & 20.27 \\
00122L & Friuli, Italy & $06 / 05 / 1976$ & 6.5 & 33.3 & 275 & 0.08 & 9.60 \\
01177L & Kocaeli, Turkey & $17 / 08 / 1999$ & 7.5 & 52.0 & 275 & 0.11 & 16.81 \\
01144L & Gulf of Aqaba & $22 / 11 / 1995$ & 7.2 & 43.3 & 355 & 0.10 & 11.49 \\
00138L & Tabas, Iran & $16 / 09 / 1978$ & 7.4 & 24.1 & 339 & 0.11 & 19.61 \\
01155L & Kocaeli, Turkey & $17 / 08 / 1999$ & 7.5 & 60.4 & 275 & 0.10 & 18.86 \\
\hline
\end{tabular}

Table 7: Limit levels of peak angle change (rad) for three performance levels, for cross section Classes 1 and 2

\begin{tabular}{cccc}
\hline \multirow{2}{*}{ Class of cross section } & \multicolumn{3}{c}{ Limit State } \\
& DL & SD & NC \\
\hline 1 & 0.05 & 0.10 & 0.19 \\
2 & & & 0.14 \\
\hline
\end{tabular}




\section{Figures}

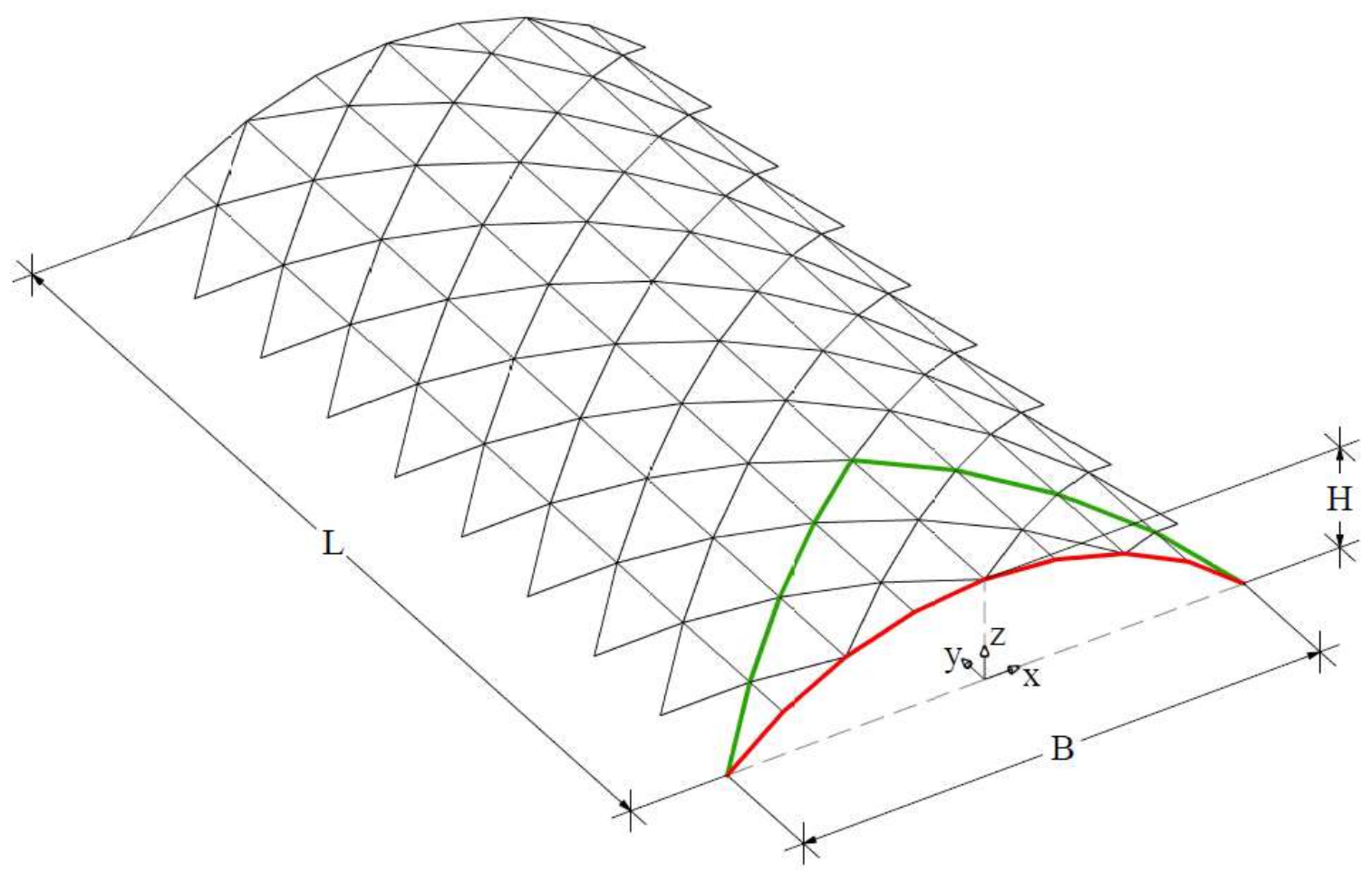

Figure 1: General configuration of single layer cylindrical lattice shells

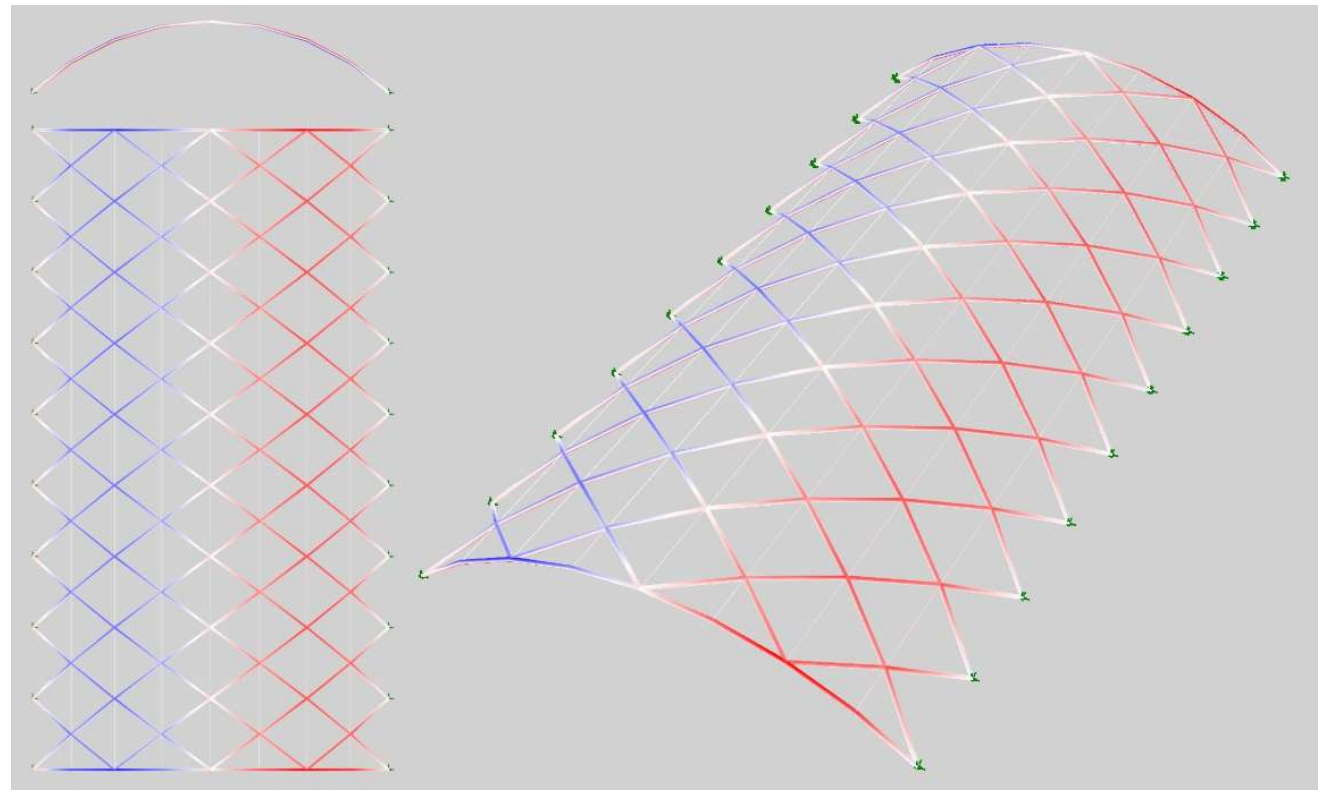

Figure 2: Stress concentrations at the quarter points of the shell when subjected to horizontal loads 

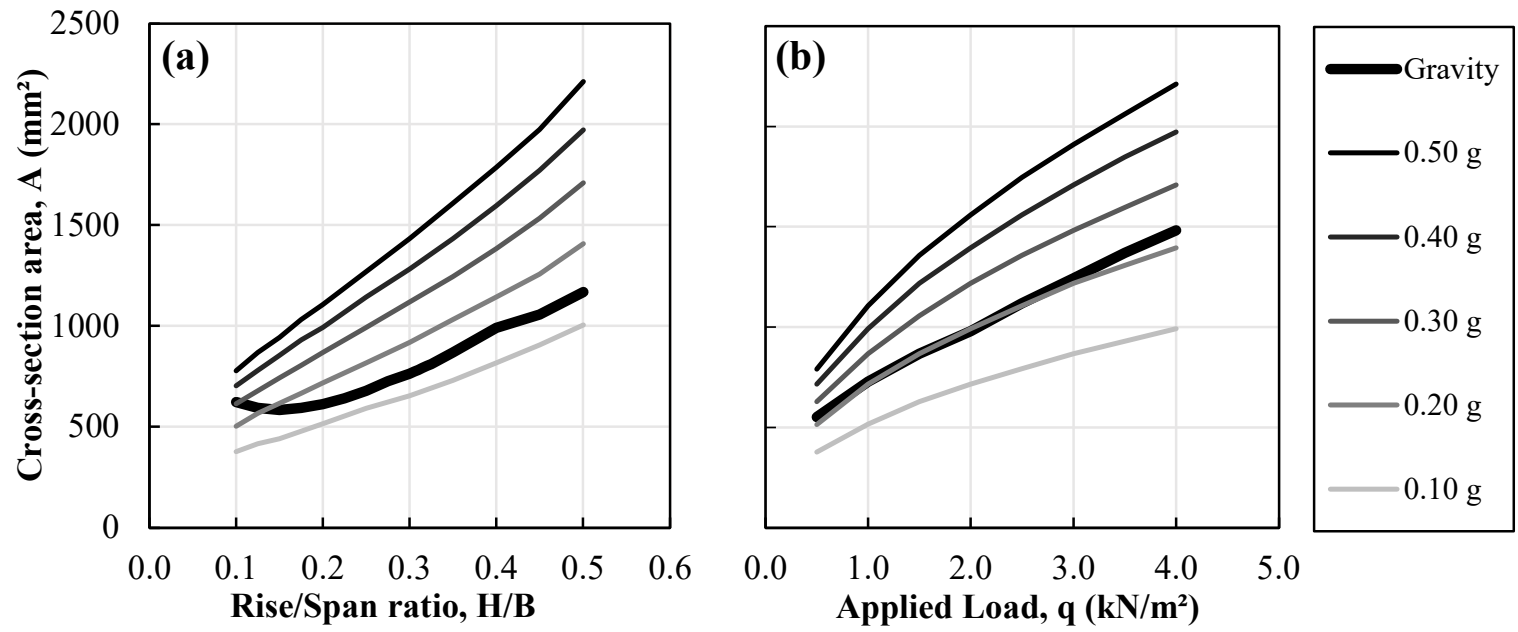

Figure 3: Cross-sectional area of diagonal and longitudinal members against rise to span ratio (for an applied load of $\mathrm{q}=1.0 \mathrm{kN} / \mathrm{m}^{2}$ ) (a) and applied load (for the case of $\left.\mathrm{H} / \mathrm{B}=0.2\right)(\mathrm{b})$, for increasing levels of gravity load applied horizontally, compared to the gravity load case
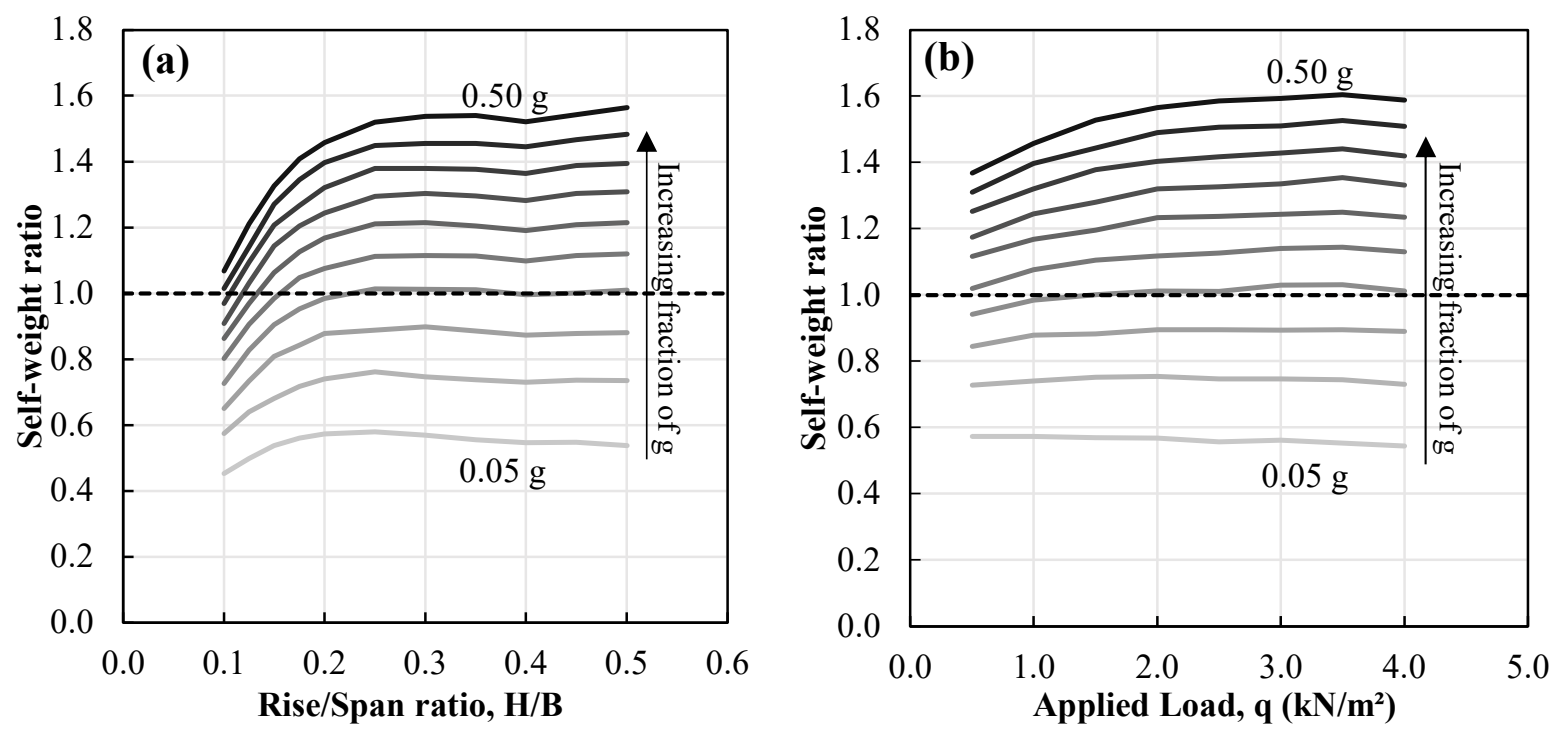

Figure 4: Ratio of self-weight of the structure designed for horizontal loads to the self-weight of the structure designed for gravity loads against rise to span ratio (a) and applied load (b), in increments of $0.05 \mathrm{~g}$

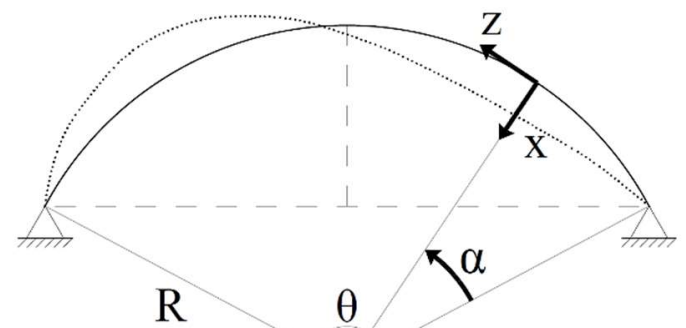

Figure 5: Parameters defining the first mode shape of a shell with unrestrained edge arches 


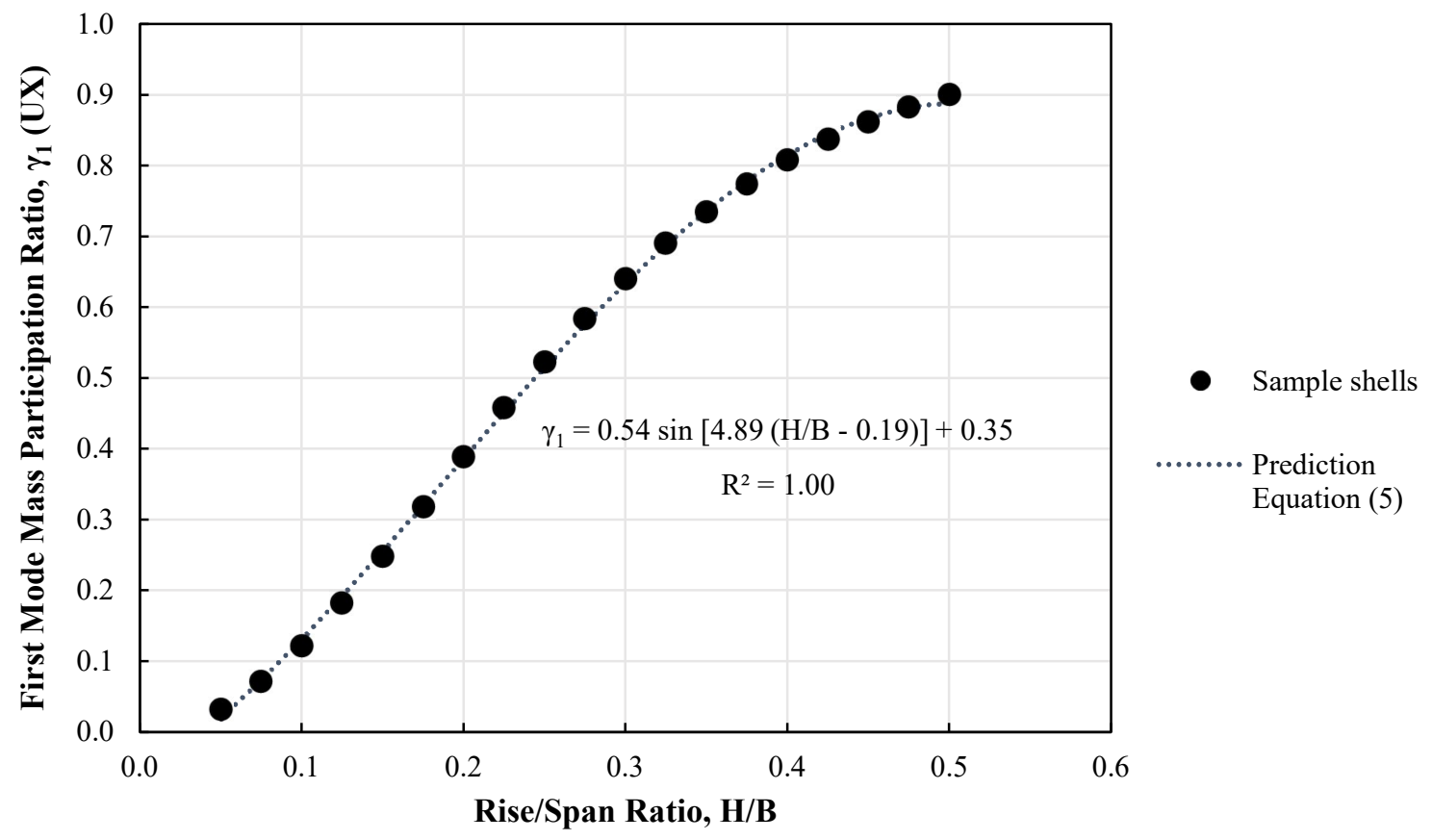

Figure 6: First mode mass participation factor estimated from the rise to span ratio

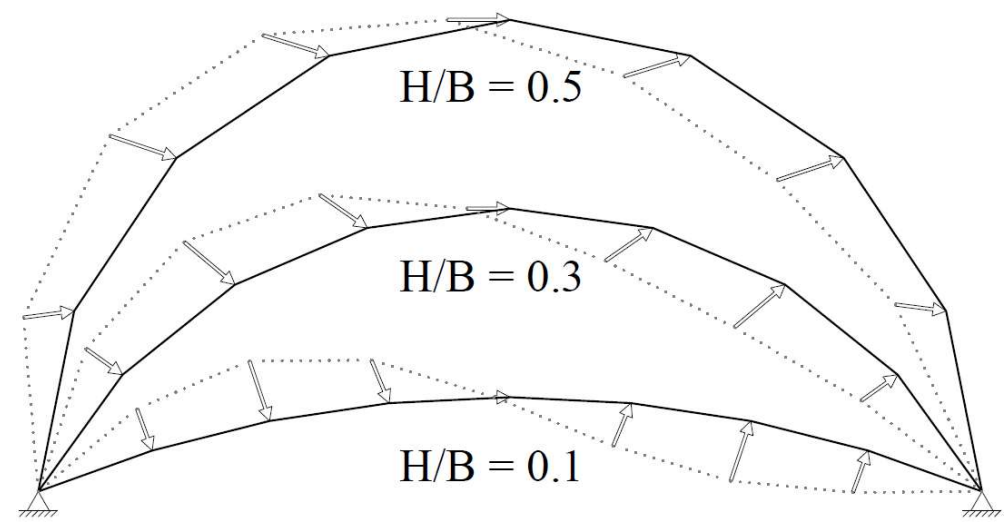

Figure 7: Load cases used to predict seismic forces in the shells, proportional to the nodal displacements of the first mode shape, shown for three representative rise to span ratios 

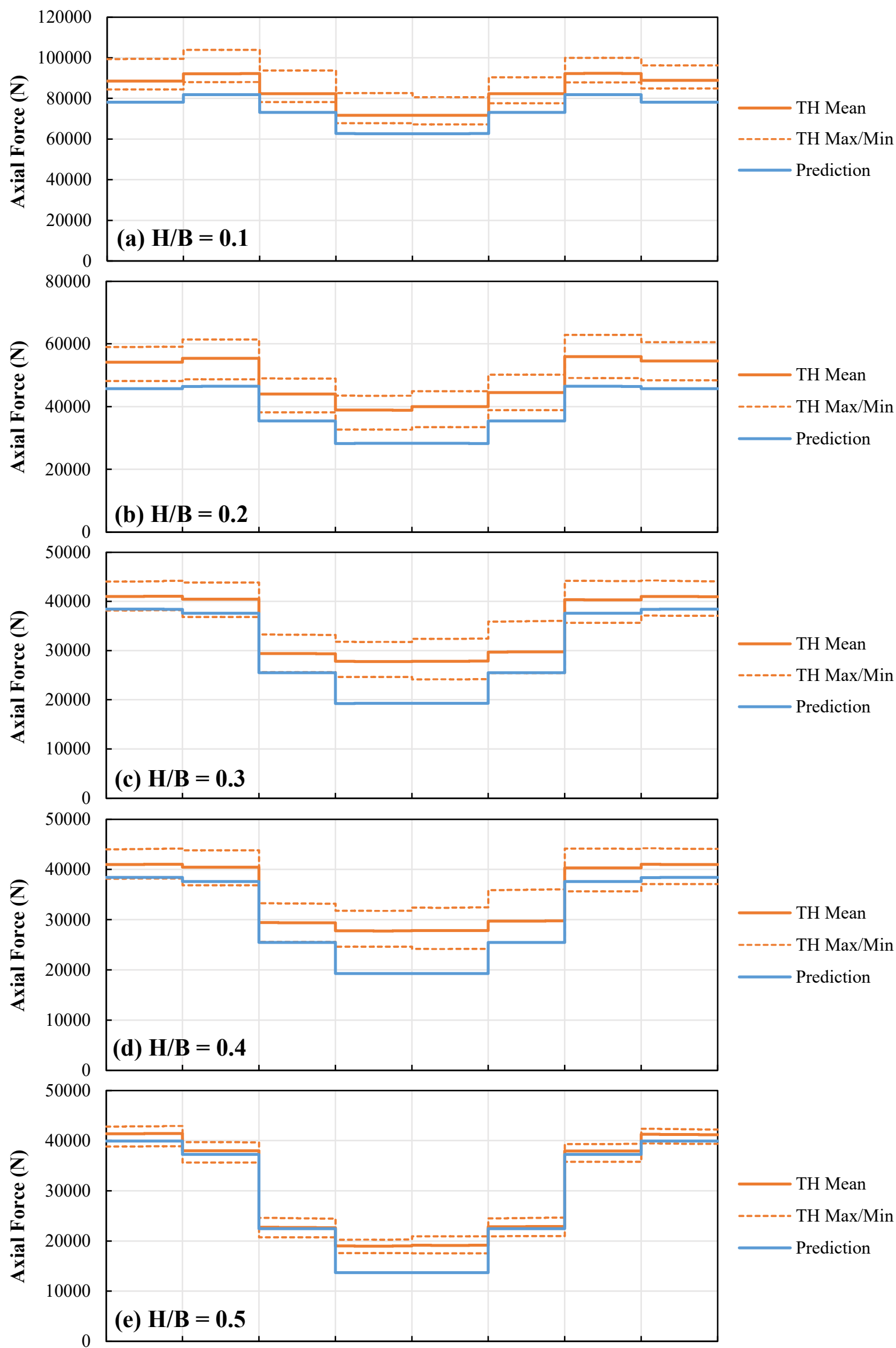

Figure 8: Comparison of axial forces between prediction and horizontal time history analyses 

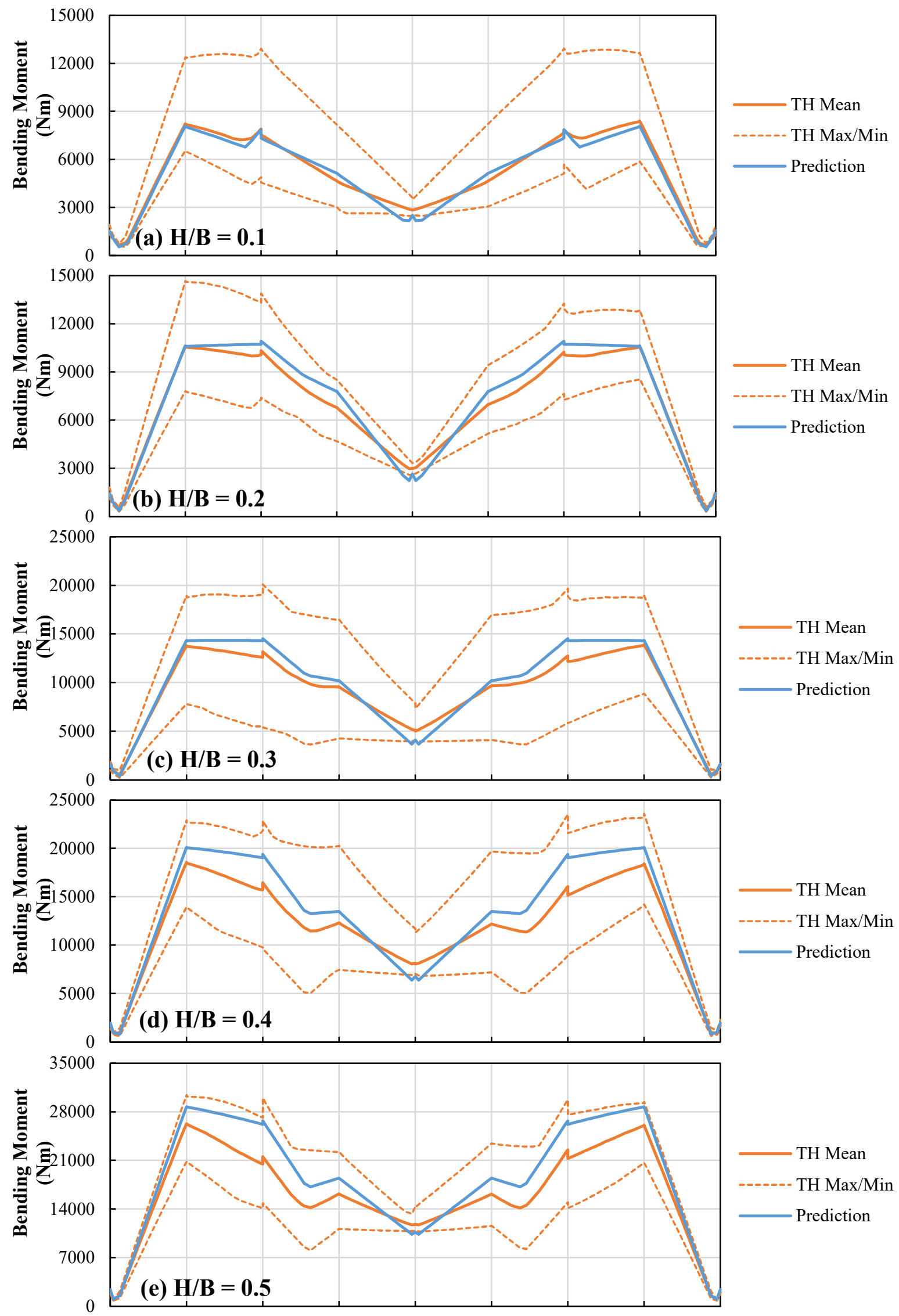

Figure 9: Comparison of bending moments between prediction and horizontal time history analyses 
(a) Undeformed shape

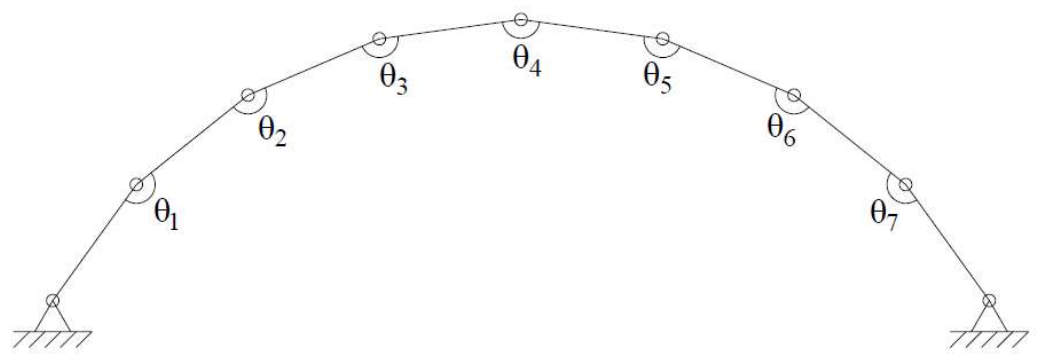

(b) Deformed shape at a given time step

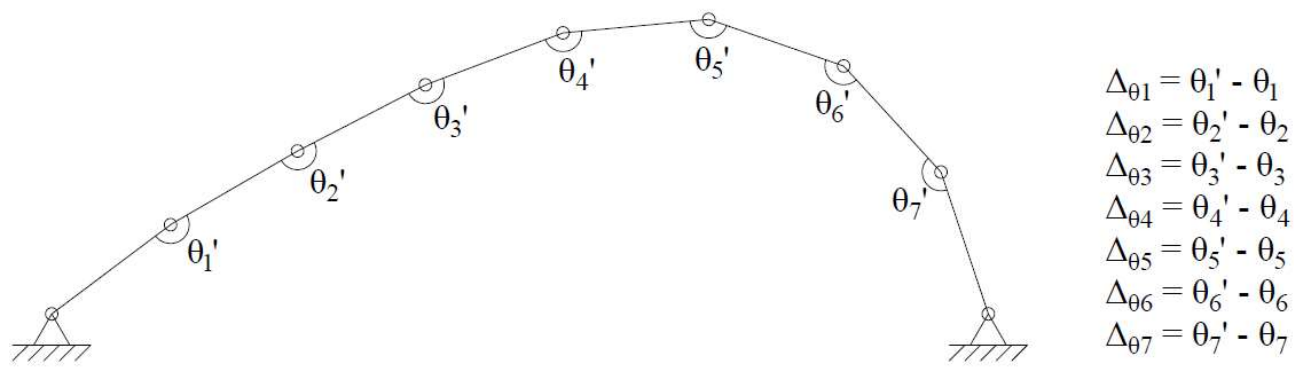

Peak Angle Change, $\Delta_{\theta, \max }=\max \left(\left|\Delta_{\theta 1}\right|,\left|\Delta_{\theta 2}\right|,\left|\Delta_{\theta 3}\right|,\left|\Delta_{\theta 4}\right|,\left|\Delta_{\theta 5}\right|,\left|\Delta_{\theta 6}\right|,\left|\Delta_{\theta 7}\right|\right)$

Figure 10: Peak angle change considered as the maximum change in angle (b) from the original angles in the undeformed shape (a)
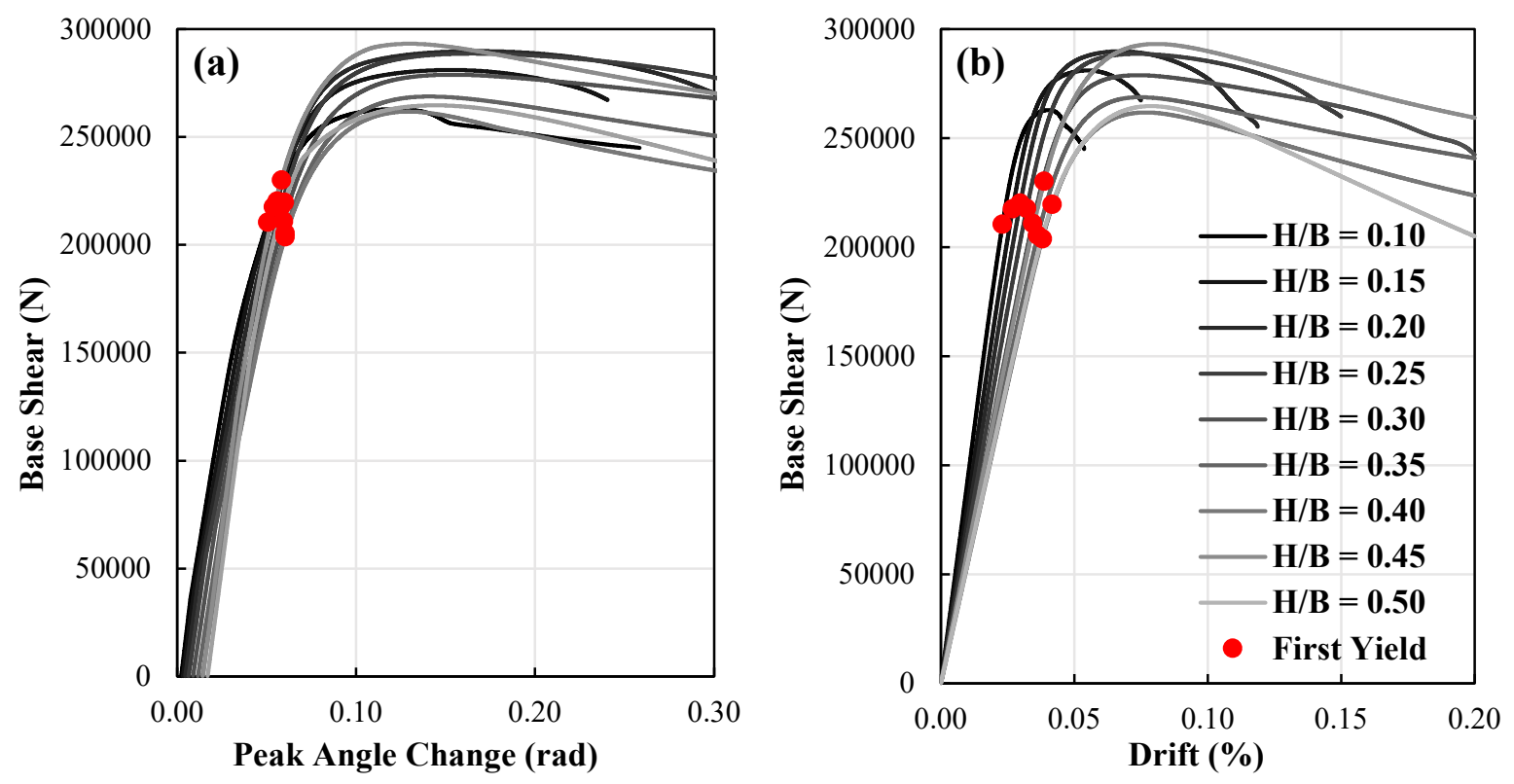

Figure 11: Pushover analysis results with respect to peak angle change (a) and drift (b). 


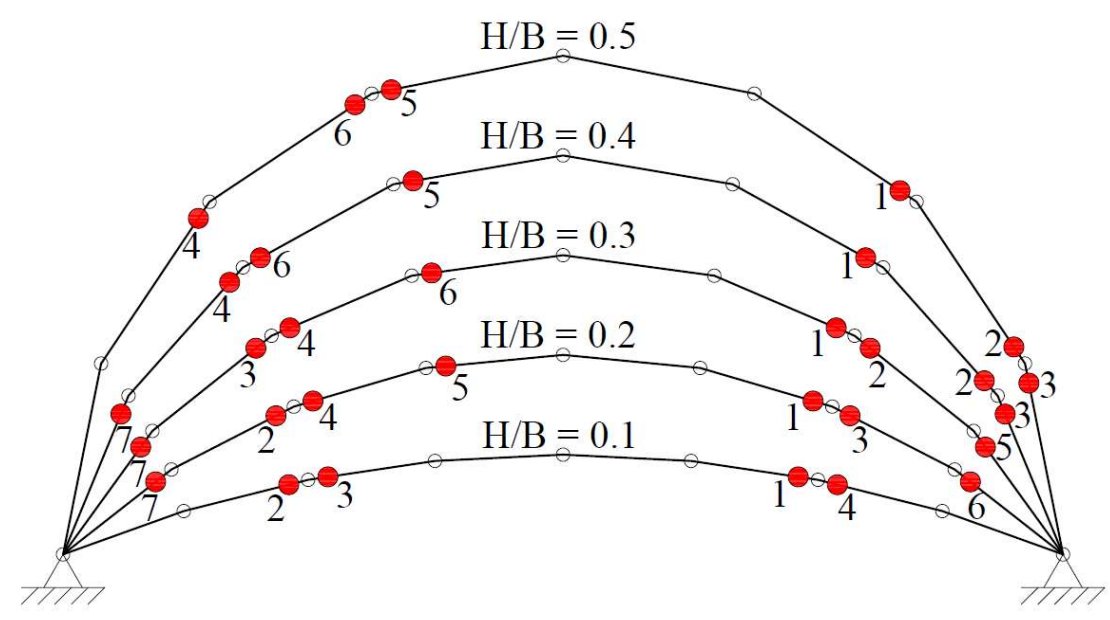

Figure 12: Spread of plasticity and development of plastic hinge for five representative values of $\mathrm{H} / \mathrm{B}$, with numbers indicating the plastic hinge formation order [33] 

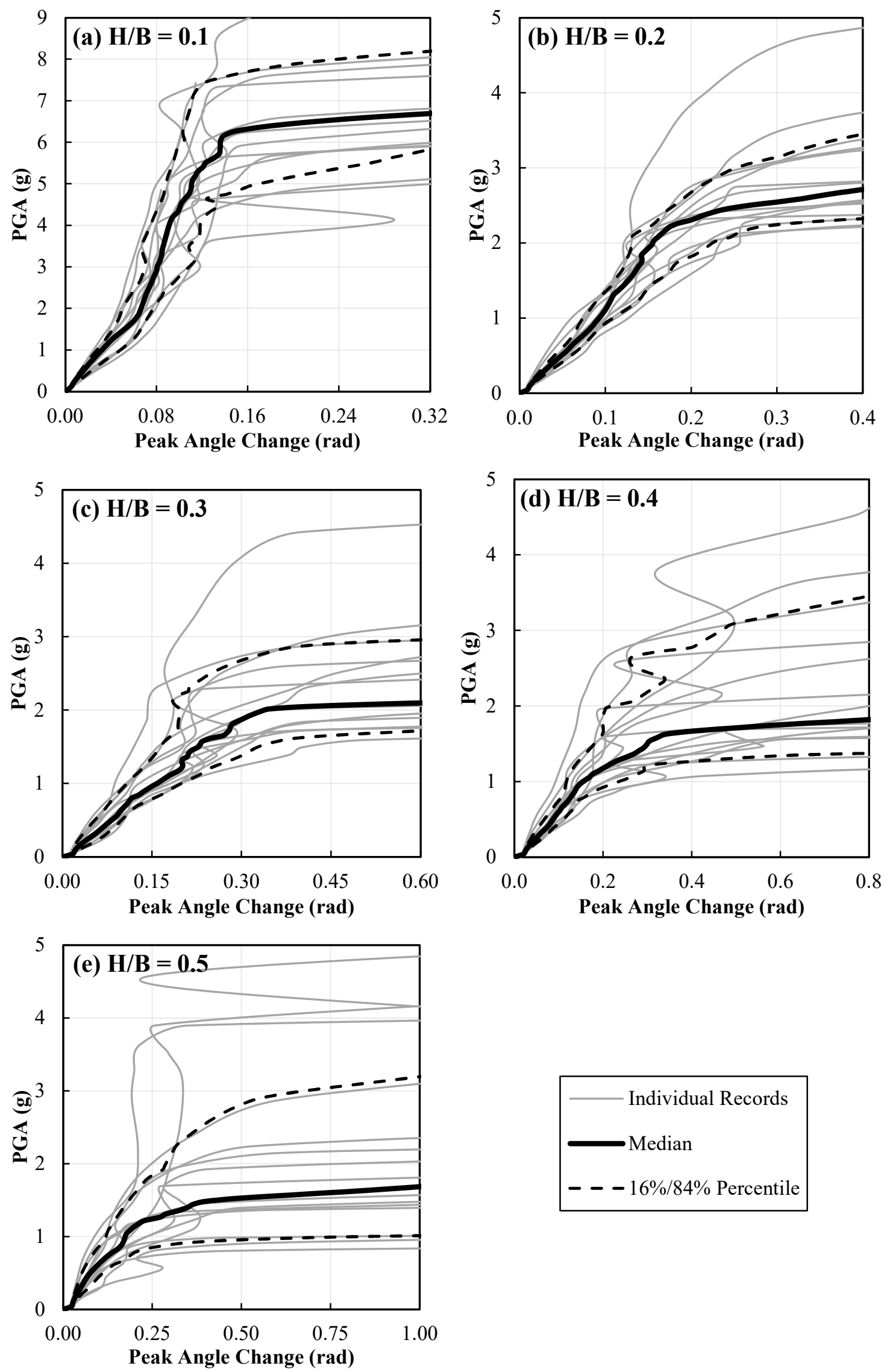

Figure 13: Incremental dynamic analysis results for five representative values of H/B 


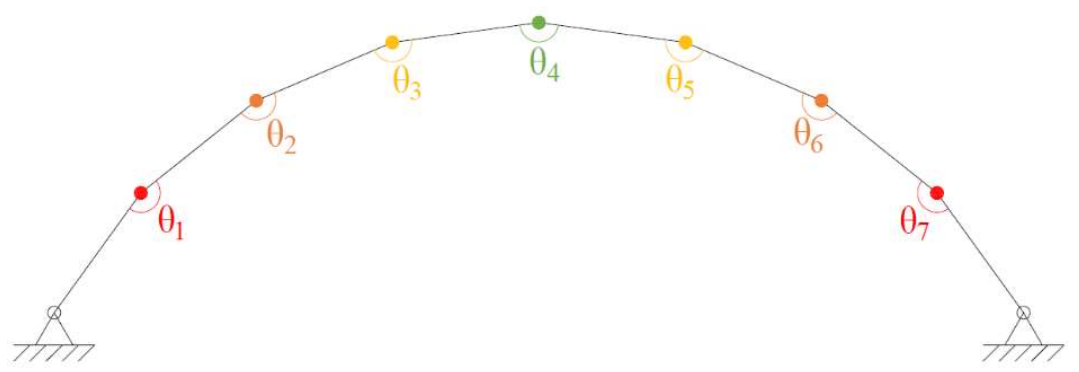

Figure 14: Colour pairing of angles that are symmetrical to each other 

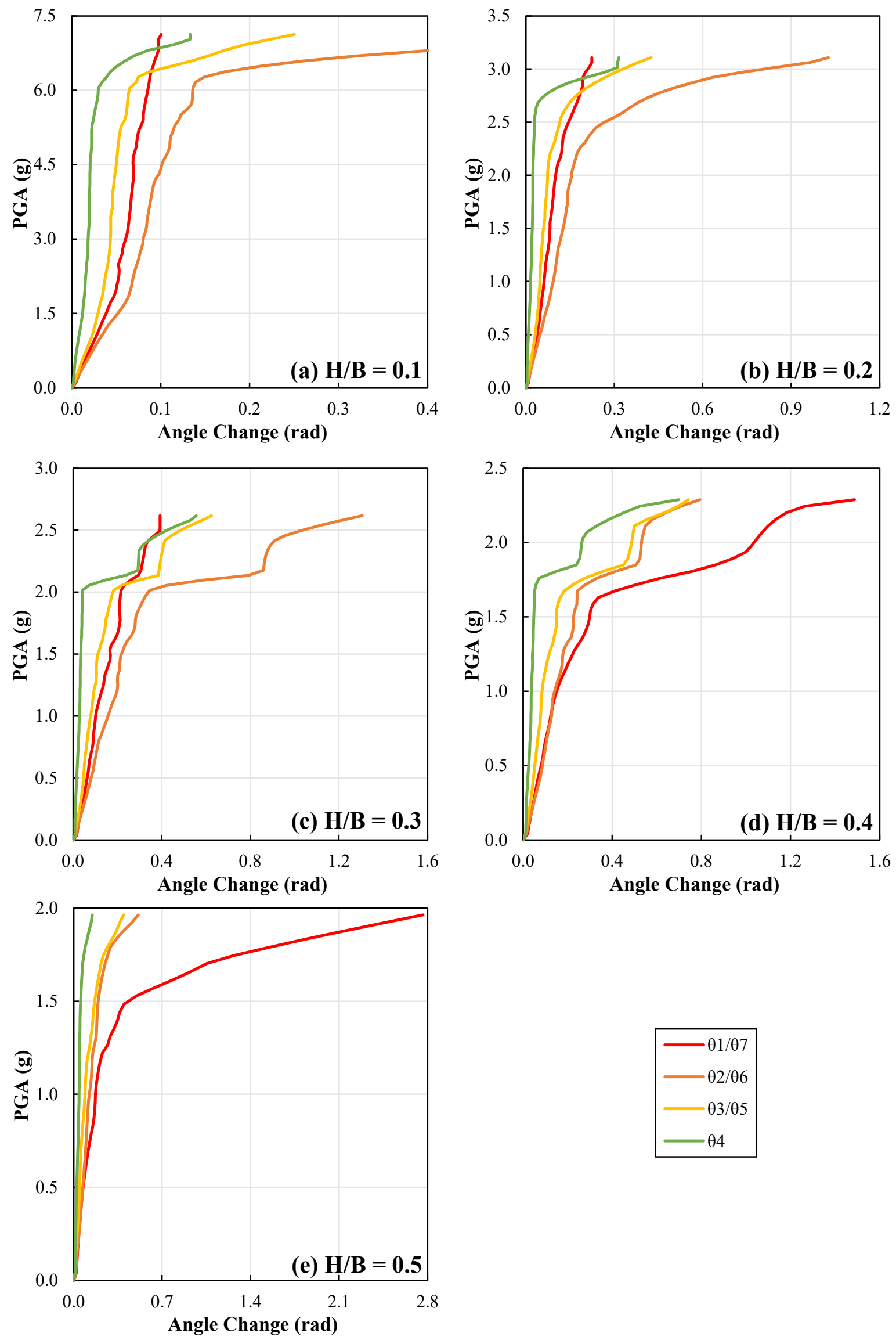

Figure 15: Median individual angle changes for shells of five representative values of H/B 

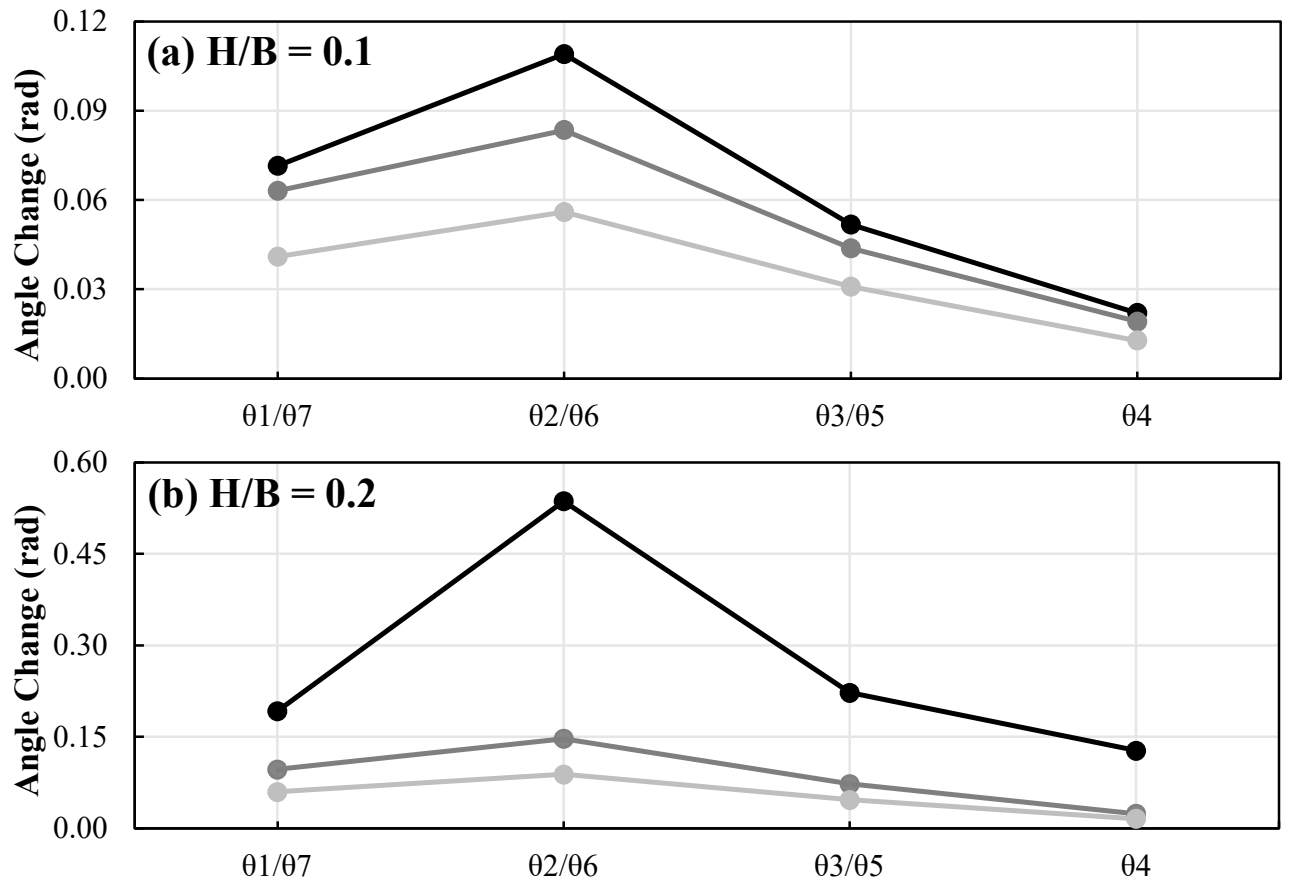

PGA (g)

$-2.85$

$-1.90$

$\multimap 0.95$

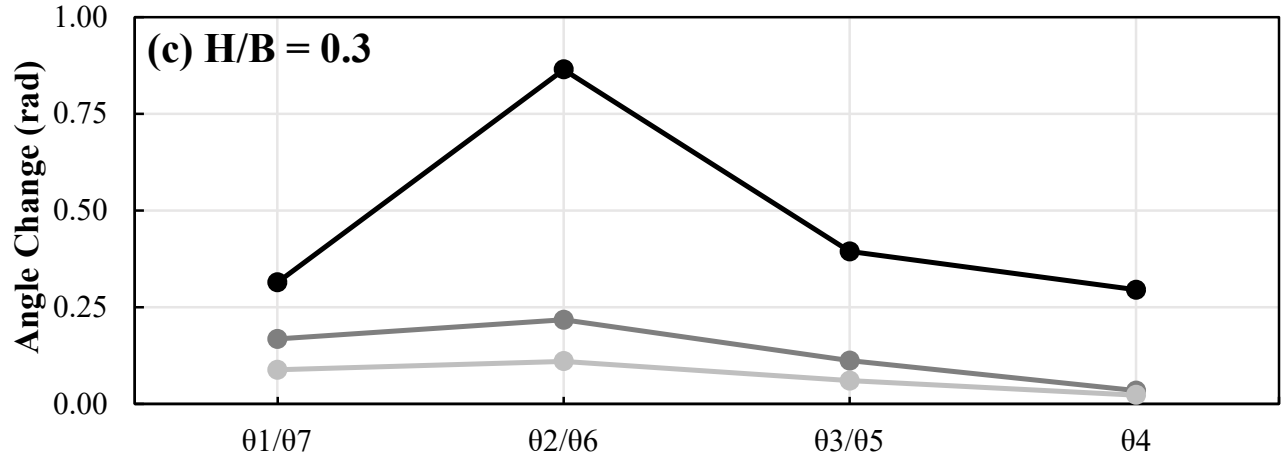

PGA (g)

$\rightarrow-2.25$

$-1.50$

$-0.75$

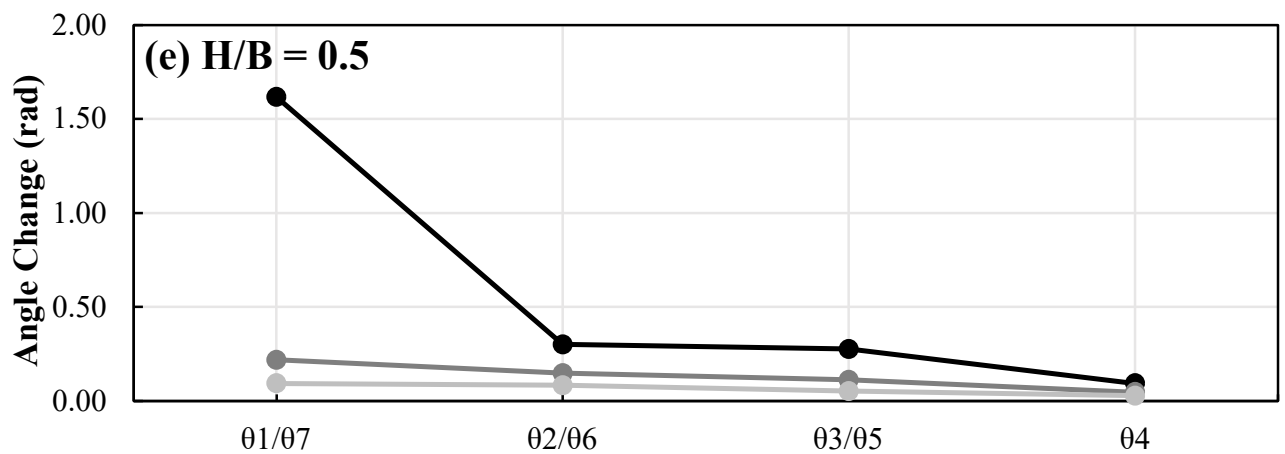

PGA (g)

$\longrightarrow-1.80$

$-1.20$

$\longrightarrow 0.60$

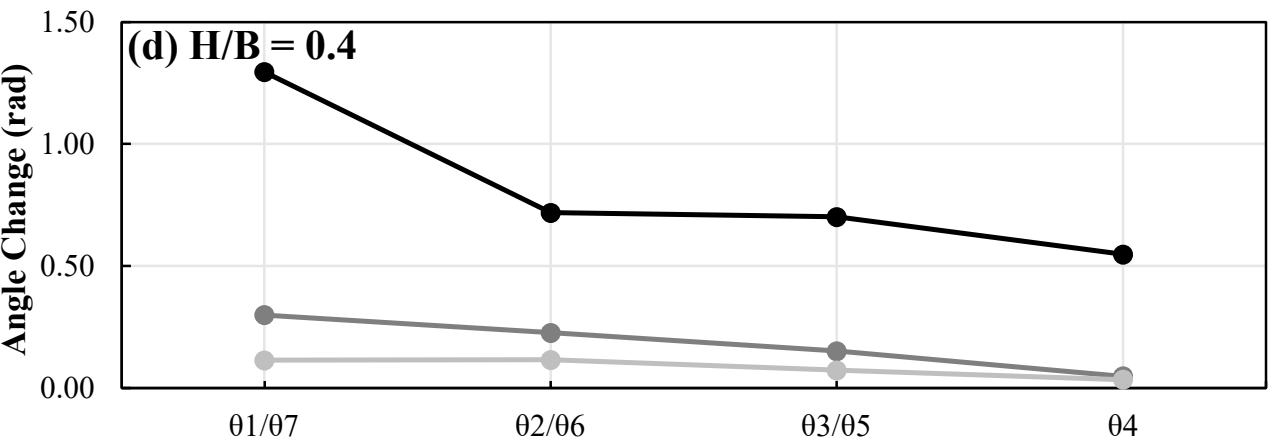

PGA (g)

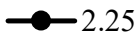

$-1.50$

$-0.75$

Figure 16: Values of angle changes in the individual angles at three increasing levels of PGA for five representative values of $\mathrm{H} / \mathrm{B}$ 
(a) $\mathrm{H} / \mathrm{B}=\mathbf{0 . 1}$

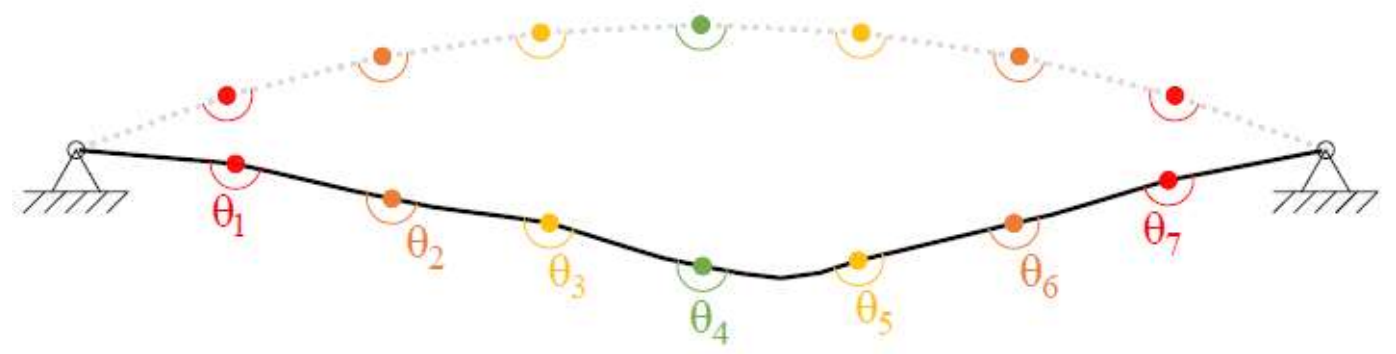

(b) $\mathrm{H} / \mathrm{B}=\mathbf{0 . 5}$

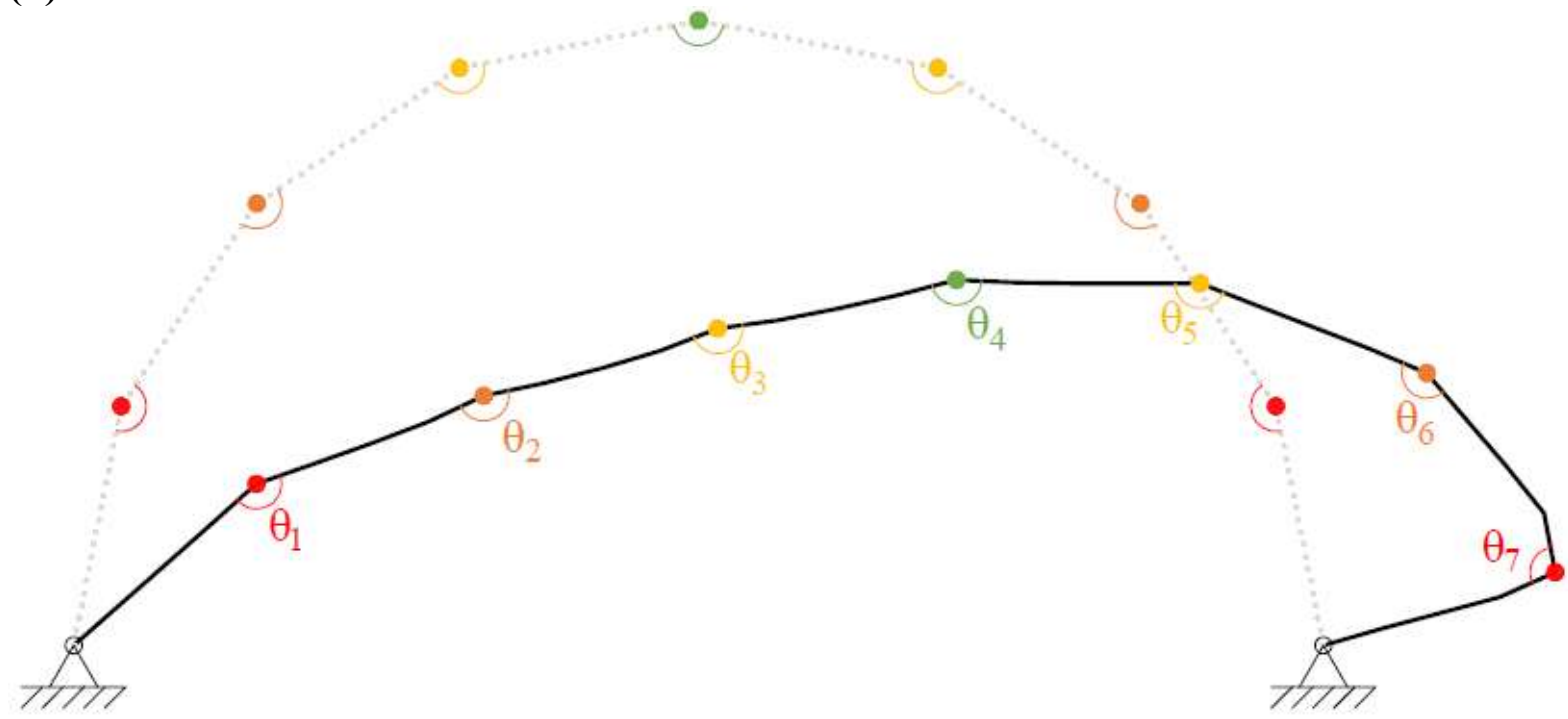

Figure 17: (a) Deformed shape at collapse for $\mathrm{H} / \mathrm{B}=0.1$. (b) Deformed shape at collapse for $\mathrm{H} / \mathrm{B}=0.5$ 

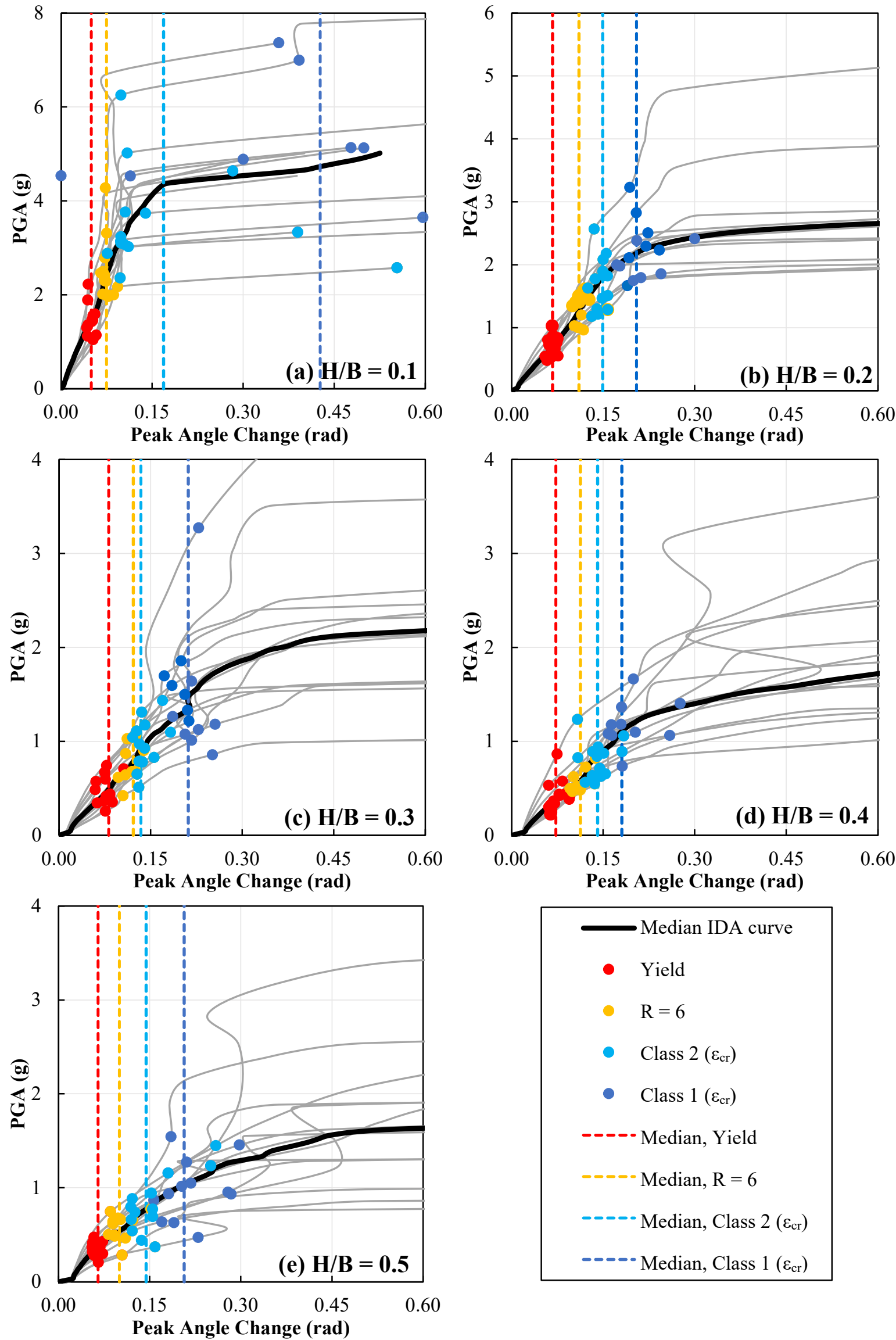

Figure 18: (a-e) Limit conditions in the shells from IDA for five representative rise to span ratios 


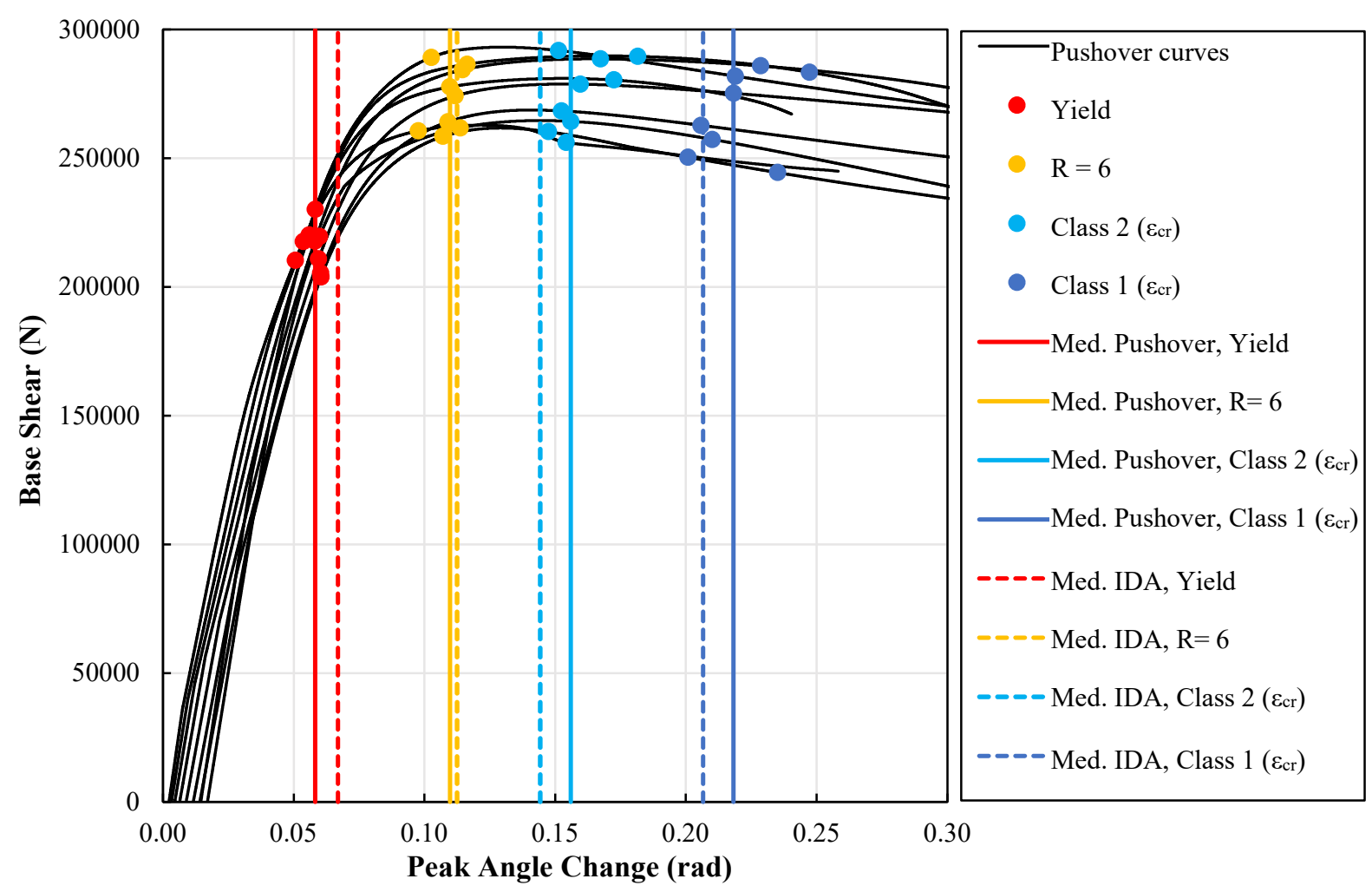

Figure 19: Limit conditions from the pushover analyses for all the shells

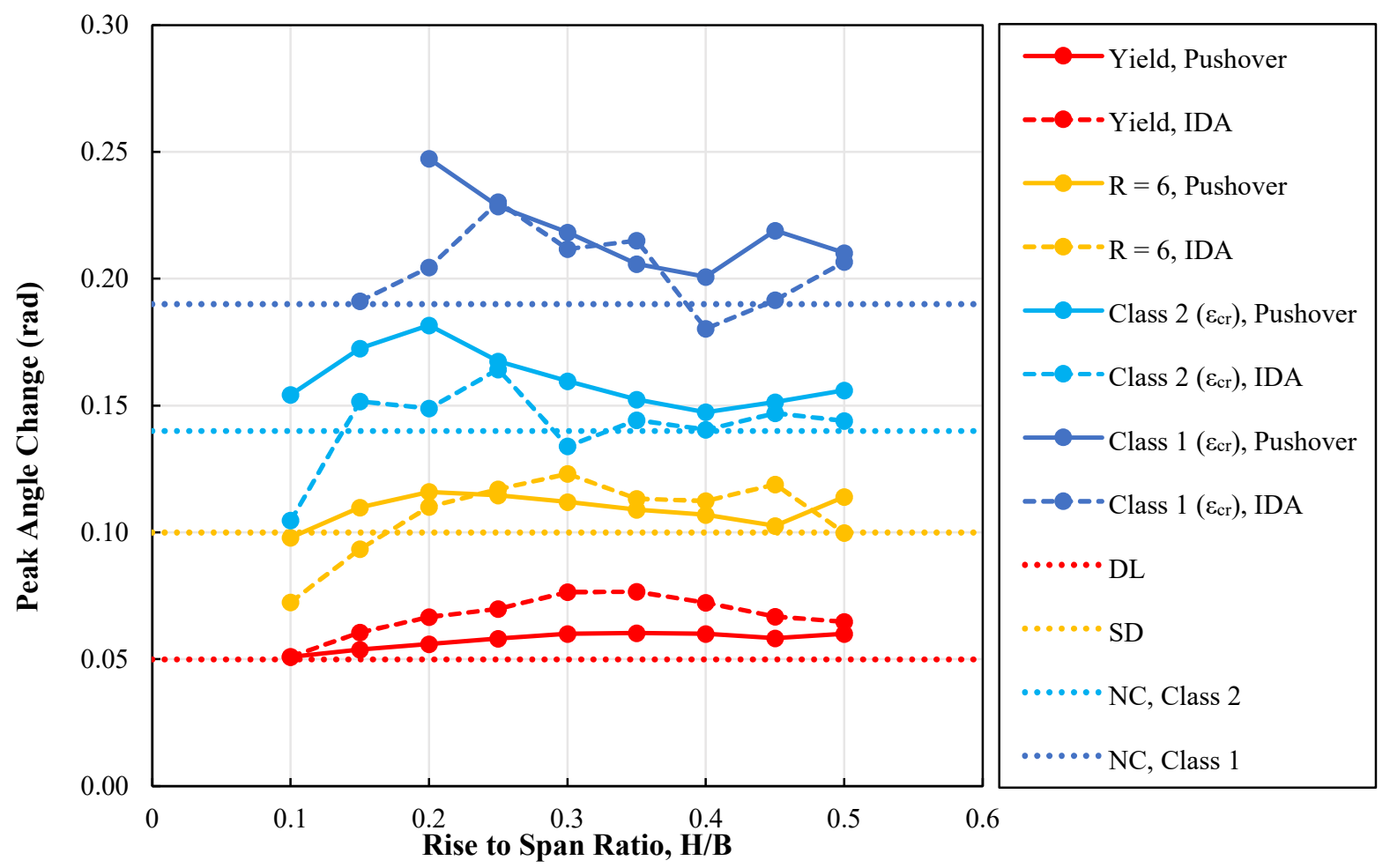

Figure 20: Comparative limit points from IDA and pushover alongside associated performance levels 


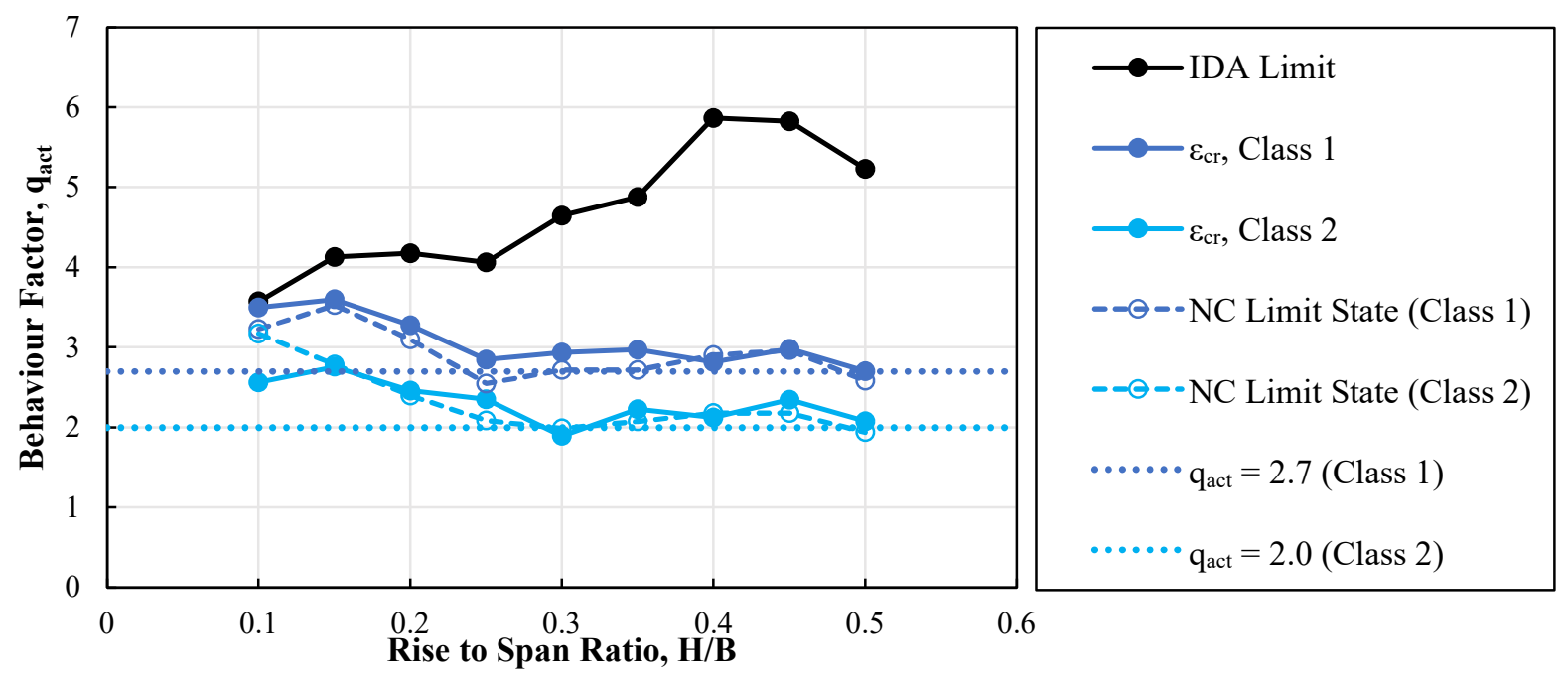

Figure 21: Behaviour factors corresponding to different collapse criteria

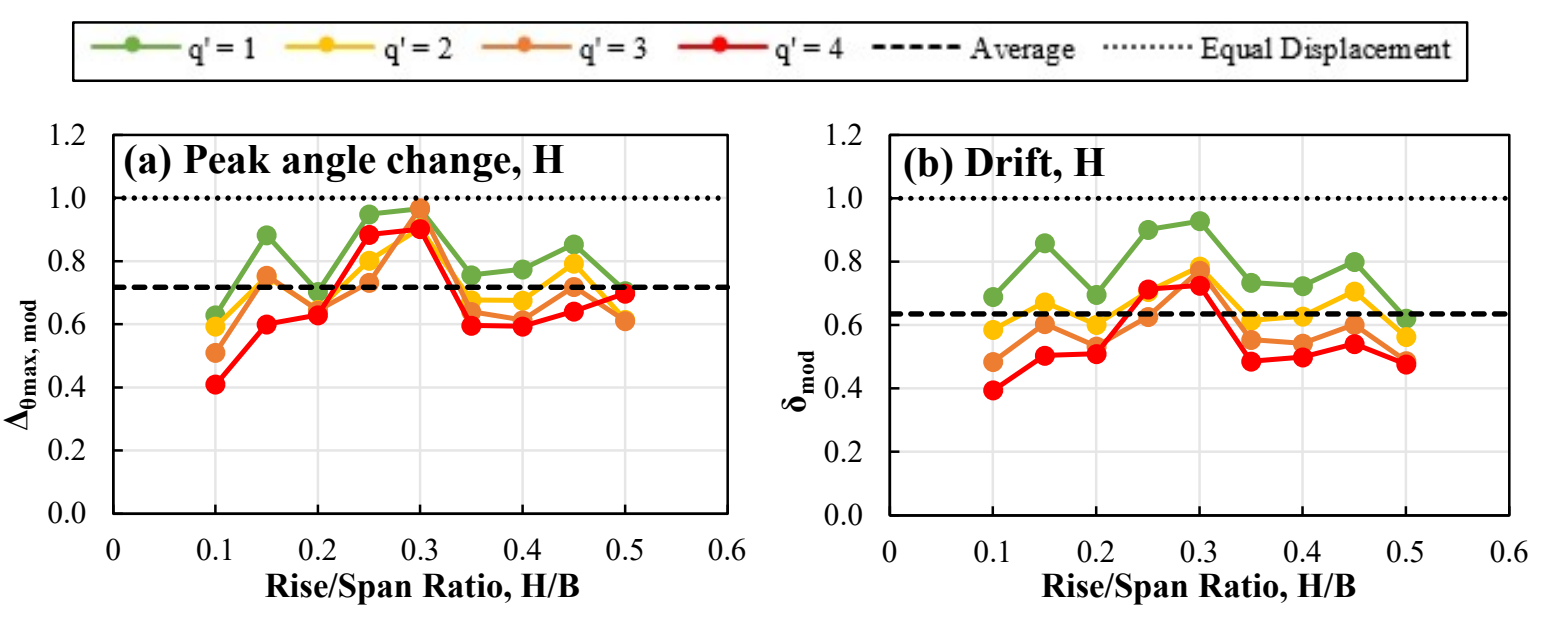

Figure 22: Modification factors for peak angle change (a) and drift (b)
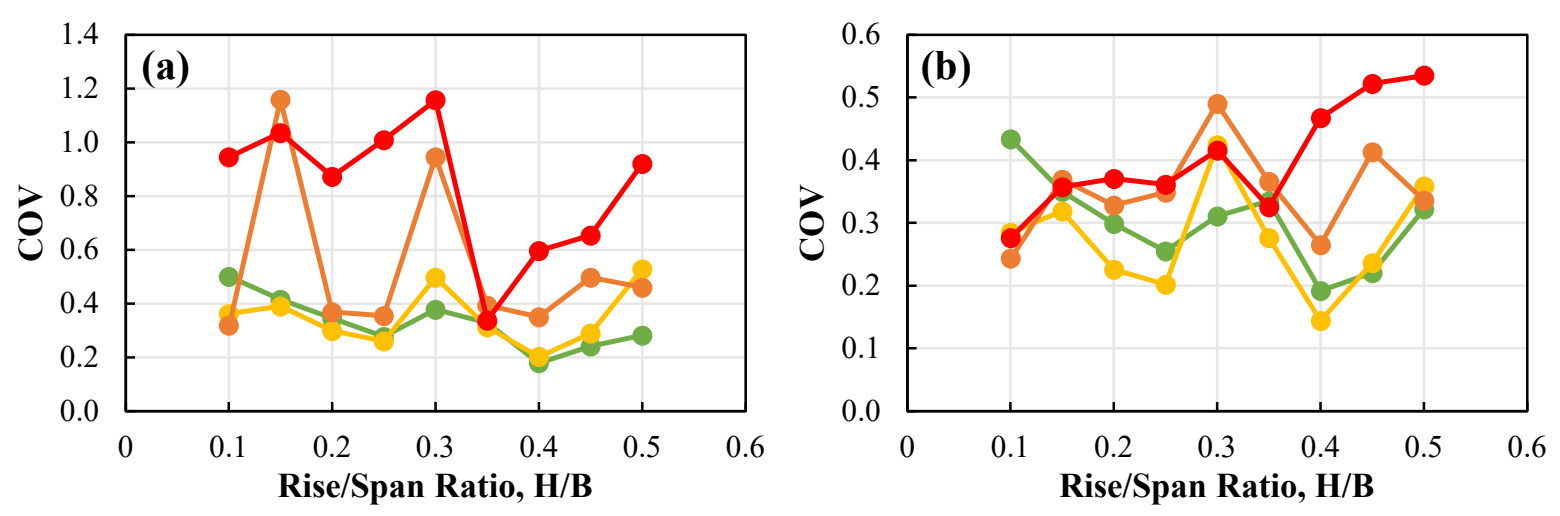

Figure 23: $\mathrm{CoV}$ for the modification factors for peak angle change (a) and drift (c) 